\title{
p27 Kip1 controls cytokinesis via the regulation of citron kinase activation
}

\author{
Murielle P. Serres, ,1,3 Uta Kossatz, ${ }^{4}$ Yong Chi, 5 James M. Roberts, ${ }^{5}$ \\ Nisar P. Malek, ${ }^{4}$ and Arnaud Besson ${ }^{1,2,3}$
}

\begin{abstract}
${ }^{1}$ INSERM UMR1037, Cancer Research Center of Toulouse, Toulouse, France. ${ }^{2}$ Université de Toulouse, Toulouse, France. ${ }^{3}$ CNRS ERL5294, Toulouse, France. ${ }^{4}$ Medizinische Universitätsklinik, Abteilung Innere Medizin 1, Tübingen, Germany. ${ }^{5}$ Fred Hutchinson Cancer Research Center,
\end{abstract} Division of Basic Sciences, Seattle, Washington, USA.

\begin{abstract}
$\mathrm{p}^{27 \mathrm{Kip} 1}$ (p27) acts as a tumor suppressor by inhibiting cyclin-cyclin-dependent kinase (cyclin-CDK) activity. However, mice expressing a form of $\mathrm{p} 27$ that is unable to bind or inhibit cyclin-CDK complexes $\left(\mathrm{p}^{\left.27^{\mathrm{CK}}-\right)}\right.$ have increased incidence of tumor development as compared with wild-type and $p 27^{-/}$mice, revealing an oncogenic role for $\mathrm{p} 27$. Here, we identified a phenotype of multinucleation and polyploidy in $\mathrm{p}^{27^{C K}-}$ mice not present in $p 27^{-/-}$animals, suggesting a role for $\mathrm{p} 27$ in $\mathrm{G}_{2} / \mathrm{M}$ that is independent of cyclin-CDK regulation. Further analysis revealed that $\mathrm{p} 27^{\mathrm{CK}}-$ expression caused a cytokinesis and abscission defect in mouse embryonic fibroblasts. We identified the Rho effector citron kinase (citron-K) as a $\mathrm{p} 27$-interacting protein in vitro and in vivo and found that $\mathrm{p} 27$ and citron-K colocalized at the contractile ring and mid-body during telophase and cytokinesis. Moreover, overexpression of the minimal $\mathrm{p} 27$-binding domain of citron- $\mathrm{K}$ was sufficient to rescue the phenotype caused by $\mathrm{p}^{2 \mathrm{CK}-}$. Conversely, expression of a mutant $\mathrm{p} 27^{\mathrm{CK}-}$ unable to bind citron-K did not induce multinucleation. Finally, by binding to citron-K, p27 prevented the interaction of citron-K with its activator RhoA. Taken together, these data suggest a role for $\mathrm{p} 27$ during cytokinesis via the regulation of citron-K activity.
\end{abstract}

\section{Introduction}

The kinase activity of cyclin-cyclin-dependent kinase (cyclin$\mathrm{CDK}$ ) complexes is tightly regulated at several levels, one of which is provided by the association with CDK inhibitors (CKIs) $(1,2)$. The importance of the CKI p27 ${ }^{\mathrm{Kip} 1}$ (p27) as a negative regulator of cell proliferation is illustrated by the phenotype of $\mathrm{p}^{27^{-1-}}$ mice, which exhibit an increase in body size and multiorgan hyperplasia and are predisposed to spontaneous and carcinogen-induced tumorigenesis (3-6). Consistent with a tumor suppressor role for p27, loss of p27 in the nuclei of tumor cells is frequent in human tumors, and this is associated with high-grade tumors and poor prognosis $(7,8)$. However, in contrast to conventional tumor suppressors such as $\mathrm{p} 53$ or $\mathrm{Rb}$, loss of $\mathrm{p} 27$ expression most commonly occurs not through genetic mutations or epigenetic silencing, but rather via increased proteolytic degradation, relocalization in the cytoplasm, or transcriptional repression $(2,8,9)$.

p27 also has roles independent of its cyclin-CDK inhibitory function (2). For instance, p27 prevents activation of the GTPase RhoA, thereby regulating actin cytoskeleton dynamics, and this function is important for cortical neuron migration during embryonic development in mice $(10,11)$. The inhibition of RhoA activity by p27 has also been shown to promote tumor cell migration and invasion and tumor metastasis in vivo $(12,13)$. To investigate the cyclin-CDK-independent functions of $\mathrm{p} 27$, we generated $\mathrm{p} 27^{\mathrm{CK}-}$ knock-in mice, in which p 27 can no longer interact with or inhibit cyclins and CDKs $(14,15)$. These mice have an increased incidence of spontaneous and chemically induced tumors in different organs compared with $p 27^{-1-}$ mice, indicating an oncogenic role for $\mathrm{p} 27$ distinct from its role in cyclin-CDK inhibition $(15,16)$.

The prominent role of $\mathrm{p} 27$ at the $\mathrm{G}_{0} / \mathrm{G}_{1}$ and $\mathrm{G}_{1} / \mathrm{S}$ transitions of the cell cycle has been extensively studied $(1,2,8)$. Indeed, p27

Conflict of interest: The authors have declared that no conflict of interest exists. Citation for this article: J Clin Invest. 2012;122(3):844-858. doi:10.1172/JCI60376. levels are high in quiescent cells and decrease during the $\mathrm{G}_{1}$ phase, remaining low throughout $S$ and $\mathrm{G}_{2} / \mathrm{M}(14,17,18)$. The role of p27 in the late phases of cell cycle is less clear, but several lines of evidence point toward an important role for $\mathrm{p} 27$ in $\mathrm{G}_{2} / \mathrm{M}$. The knockout of Skp2, one of the F-box proteins targeting $\mathrm{p} 27$ for ubiquitination, leads to impaired degradation of several proteins, including cyclin E and p27 (19). In Skp2 $2^{-/-}$mice, several tissues and mouse embryonic fibroblasts (MEFs) display an increase in cell size and DNA content, centrosome amplification, and proliferation defects (19-21). These phenotypes are completely rescued in double $S k p 2^{-/-} p 27^{-/-}$mice, indicating that the accumulation

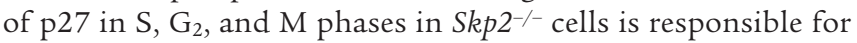
a failure to progress to mitosis, resulting in polyploidy $(20,21)$. Recently, several groups reported that ionizing radiation or DNAdamaging drugs could induce $\mathrm{p} 27$ expression to trigger an arrest in $G_{2} / M$ and that in the absence of $\mathrm{p} 27$, cells failed to undergo cell cycle arrest (22-24). Moreover, the loss of p27 was associated with increased chromosomal instability in response to DNA damage, as cells could proceed through mitosis with unrepaired DNA (22-24). In addition, p27 deficiency impeded Rad51-mediated DNA repair due to increased CDK1-mediated phosphorylation of BRCA2, which inhibits the BRCA2-Rad51 interaction and Rad51-mediated repair (22). Thus, p27 appears to play a role in the maintenance of genomic integrity and DNA damage response by participating in $\mathrm{G}_{2} / \mathrm{M}$ arrest.

Cytokinesis is the final step of the cell cycle, during which daughter cells formed in mitosis physically separate (25). While many molecules involved in the dynamic rearrangements of the cytoskeleton and membranes that take place during cytokinesis and abscission have been identified, how they coordinately orchestrate these events remains largely unclear (26). RhoA plays a key role in positioning, assembly, and contraction of the actomyosin contractile ring (27-29). Several Rho effectors have been involved in cytokinesis: $\mathrm{mDia} 2$ regulates contractile ring positioning and 
assembly (30), while ROCK1/2 and citron kinase (citron-K) are thought to regulate the assembly and contraction of the contractile ring $(27,28)$. Citron- $\mathrm{K}$ is a serine/threonine kinase with structural homology to ROCK (31-35). Three splicing isoforms are known: the full-length citron-K; citron- $\mathrm{N}$, which lacks the kinase domain and is expressed specifically in the nervous system; and citron-SK, which contains only the kinase domain $(31,36)$. During mitosis, citron-K is localized at the cleavage furrow and mid-body in a Rho-dependent manner and plays an important role in cytokinesis $(32,37)$. Overexpression in HeLa cells of a mutant form of citron-K (comprising the kinase domain, coiled-coil [CC] domain, and Rho-binding domain [RBD] but lacking the $\mathrm{C}$ terminus of the protein) caused cytokinesis failure and multinucleation or abnormal contractile ring contraction, resulting in the transfer of all the genetic material into one daughter cell (32). This latter phenotype is not observed with a kinase-dead mutant (32). Depletion of citron-K using siRNAs also leads to multinucleation in HeLa cells and hepatocellular carcinoma cells by affecting cytokinesis (38-42). On the other hand, overexpression of full-length citron-K causes only a mild multinucleation phenotype (32).

In drosophila and HeLa cells, citron-K loss of function causes defects in intercellular bridge structure and stability, delays resolution, and causes reversion of cytokinesis and multinucleation, indicating a requirement for citron- $\mathrm{K}$ at the end of cytokinesis for cellular abscission $(38,43-46)$. Both flies and mice lacking citron$\mathrm{K}$ exhibit severe phenotypes in neuroblasts and spermatocytes due to cytokinesis defect and induction of apoptosis (43, 45-48). However, other tissues, such as the imaginal disc and eye, are also affected in drosophila, suggesting a more general role for citron- $\mathrm{K}$ in cytokinesis $(45,46)$. Thus, citron-K may affect a greater diversity of cell types than has yet been studied in the knockout mice. For instance, citron-K appears to play a role in the $\mathrm{G}_{2} / \mathrm{M}$ transition of hepatocytes in rats (49). How citron-K regulates cytokinesis at the molecular level and the regulation of citron-K itself remain largely unknown. Citron-K phosphorylates the myosin II regulatory light chain in vitro (50), but there is no evidence indicating this is the case in vivo, and depletion of citron-K does not prevent contraction of the contractile ring during cytokinesis $(43,44,46)$.

In this study, we identified what we believe to be a new role of p27 during cytokinesis via the regulation of citron-K activation. We found that ${ }^{27^{C K-}}$ mice have increased numbers of polyploid and multinucleated cells in the liver and kidney. Expression of p $27^{\mathrm{CK}-}$ in cells in culture also induced multinucleation. We identified citron-K as a $\mathrm{p} 27$-interacting protein and mapped the domain of interaction to a region adjacent to the RBD of citron-K. Expression of this minimal interaction domain was sufficient to reverse the phenotype caused by $\mathrm{p} 27^{\mathrm{CK}}$. Videomicroscopy analyses revealed that $\mathrm{p} 27^{\mathrm{CK}-}$ mainly caused reopening of the intercellular bridge at the end of cytokinesis, similarly to citron-K depletion. We mapped the citron-K interaction domain on p27 to the last 8 amino acids of $\mathrm{p} 27$, and a $\mathrm{p}^{27^{\mathrm{CK}-}}$ that cannot bind citron-K did not cause multinucleation. Finally, our results suggest that $\mathrm{p} 27$ competes with RhoA for binding to citron-K, thereby interfering with citron-K activation.

\section{Results}

Polyploidy, multinucleation, and centrosome amplification in $\mathrm{p} 27^{\mathrm{CK}-}$ mice. Skp2-mediated degradation requires both p27 phosphorylation by cyclin E-CDK2 and a stable interaction with cyclin-CDK complexes $(51,52)$. Consequently, due to its inability to bind cyclin-
CDKs, 2 $^{\mathrm{CK}-}$ degradation is impaired, resulting in an accumulation of the protein in $\mathrm{S} / \mathrm{G}_{2} / \mathrm{M}$, although $p 27^{C K-}$ cells retain similar kinetics of cell cycle reentry after serum stimulation compared with wild-type cells (Figure 1A and refs. 14, 52). The prominent role of Rho signaling in the control of mitosis and the ability of p27 to regulate RhoA $(10,27)$ prompted us to investigate whether p27 ${ }^{\mathrm{CK}-}$ caused an aberrant phenotype in mitosis. Histological examination of the liver tissue of P27CK- $^{2}$ mice revealed nucleus enlargement and an increased number of multinucleated cells (Figure 1, B and C). Determination of the DNA content by Feulgen staining on liver sections revealed an increased number of hepatocyte nuclei with $8 \mathrm{~N}$ and $16 \mathrm{~N}$ content in $p^{27^{C K-}}$ mice (Figure $1 \mathrm{~B}$ ) compared with age-matched $p 27^{+/+}, p 27^{-/-}$, and $p 27^{S 10 A / S 10 A}$ mice. Furthermore, we found an increased number of multinucleated hepatocytes in the liver and renal proximal tubules cells in the kidney of $p 27^{C K-}$ animals compared with $p 27^{+/+}$or $p 27^{-/-}$mice (Figure $1, C$ and D). Primary and immortalized p27CK- MEFs stained with $\beta$-catenin and lamin-A to delimit plasma membrane and nuclei, respectively, also displayed an increase in multinucleation compared with the other genotypes (Figure 2, A and B). Quantification of centrosomes using $\gamma$-tubulin as a centrosome marker showed an increase in the number of cells with extra-centrosomes in immortalized $\mathrm{p} 27^{\mathrm{CK}-}$ MEFs compared with $p 27^{+/+}$or $p 27^{-/-}$cells (Figure $2 \mathrm{C}$ ). The presence of multinucleated cells in the $\mathrm{p} 27^{\mathrm{CK}-}$ mutant suggests a defect in late mitosis, when chromosome segregation has already taken place, resulting in the formation of two nuclei. $2^{27^{\mathrm{CK}-}}$ cannot bind or inhibit cyclin-CDK complexes, suggesting that this phenotype is independent of CDK-cyclin regulation $(14,15)$. This was confirmed by monitoring the activities of cyclin A-CDK2 and cyclin B1-CDK1 complexes in asynchronous cells and populations that had been synchronized with nocodazole to enrich mitotic cells (Supplemental Figure 1; supplemental material available online with this article; doi:10.1172/ JCI60376DS1). As expected, the activity of these complexes was similarly increased in $p 27^{-1-}$ and $p 27^{\mathrm{CK}-} \mathrm{MEFs}$, and $\mathrm{p} 27^{\mathrm{CK}-}$ did not affect assembly of complexes (Supplemental Figure 1). Together, our results suggest that the presence of $\mathrm{p}^{27^{\mathrm{CK}}-}$ in the late phases of the cell cycle can lead to mitotic failure that is independent of cyclin-CDK complex regulation.

p27 ${ }^{C K-}$ expression causes a cytokinesis defect. To confirm the direct involvement of $27^{\mathrm{CK}-}$ in the multinucleation phenotype, we introduced $\mathrm{p} 27^{\mathrm{CK}-}$ by retroviral infection in two lines of $p 27^{-1-}$ MEFs. The expression level of $\mathrm{p}^{27^{\mathrm{CK}}-}$ in MEFs following infection is shown in Figure 3A. An increase in multinucleation was observed in both lines of $p 27^{-1-}$ MEFs infected with $\mathrm{p} 27^{\mathrm{CK}-}$ compared with the parental lines (Figure 3A). Interestingly, the proportion of mitotic cells in telophase and cytokinesis was increased in $p 27^{-/-}$MEFs expressing p27 ${ }^{\mathrm{CK}-}$, suggesting that multinucleation could result from a cell division defect in late mitosis (Figure 3A). The causative effect of p27 ${ }^{\mathrm{CK}-}$ on multinucleation was confirmed in HeLa cells transfected by $\mathrm{p} 27^{\mathrm{CK}-}$ (Figure $3 \mathrm{~B}$ ), and in these cells, there was also an increased fraction of mitotic cells in telophase/cytokinesis compared with empty vector-transfected cells (Figure 3B). A similar trend was seen in $p 27^{C K-}$ MEFs, where an increased proportion of mitotic cells was observed in cytokinesis compared with $p 27^{+/+}$and $p 27^{-/-}$cells, suggesting a delay at the end of mitosis (Figure 3C).

Videomicroscopy analyses revealed that cells expressing $\mathrm{p} 27^{\mathrm{CK}-}$ proceed normally through the different phases of mitosis but were sometimes delayed at the end of cytokinesis after contraction of the contractile ring and failed to resolve cytokinesis and undergo 
A

WT

Serum stimulation (h)

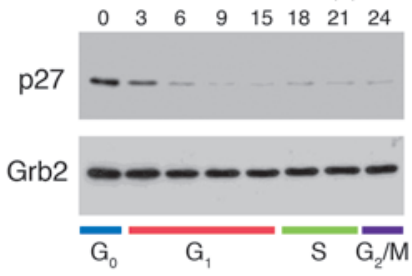

CK-

Serum stimulation (h)

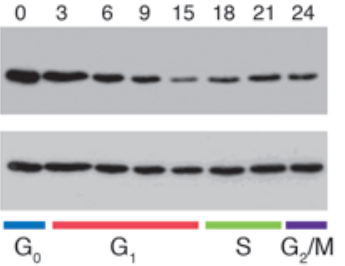

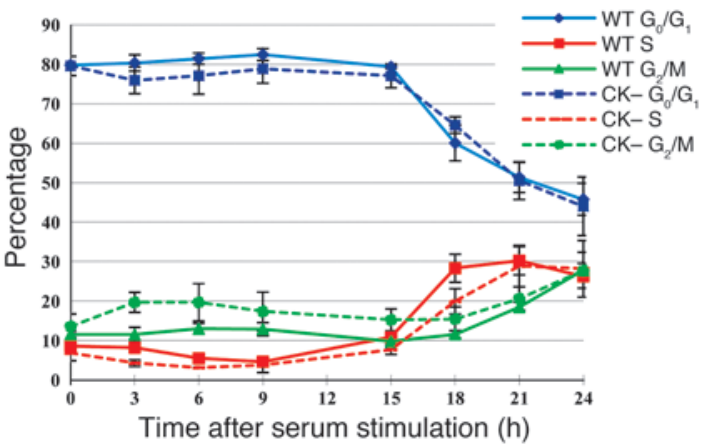

B

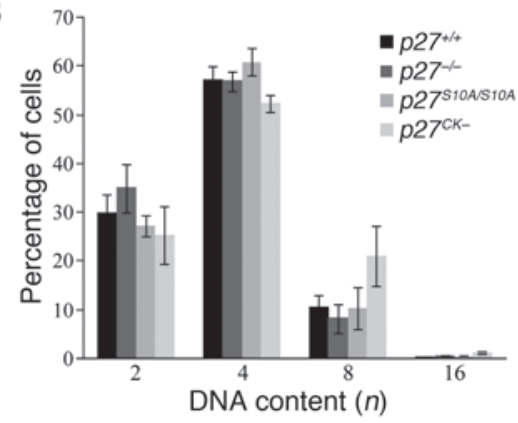

C
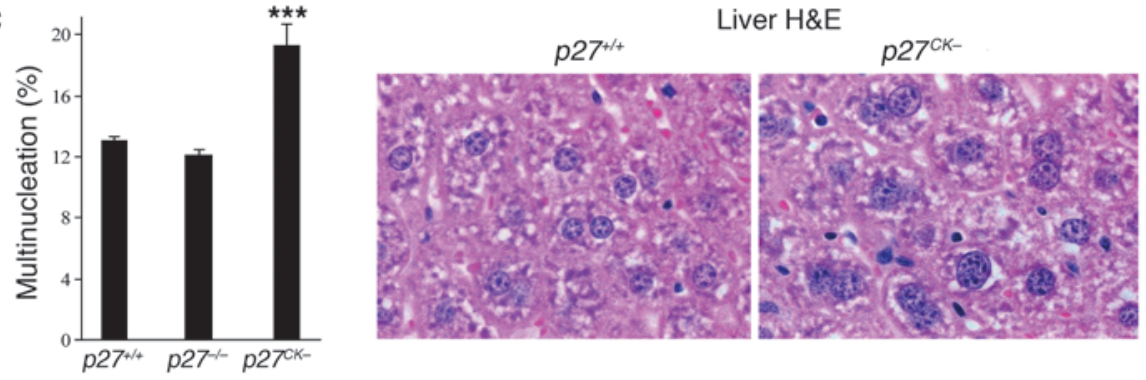

D

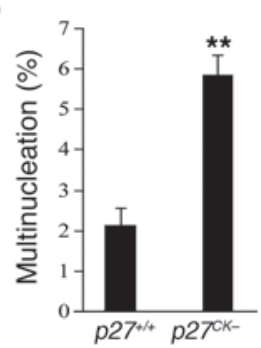

Kidney H\&E

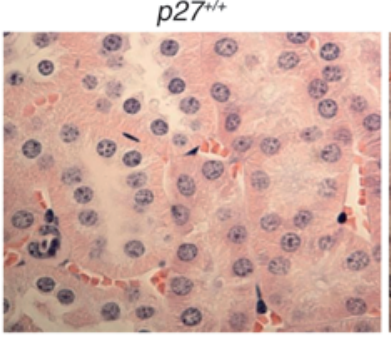

Liver H\&E

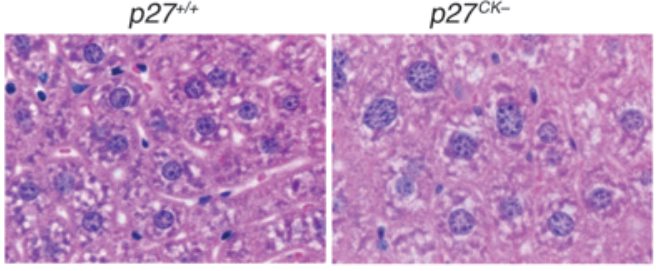

Liver H\&E

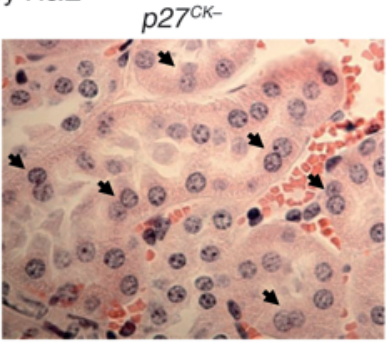

Figure 1

Polyploidy and multinucleation in the liver and kidney of p27ck- mice. (A) p27 and p27ck- expression during the cell cycle. Primary MEFs (passage 2) derived from $p 27^{+/+}$and $p 27^{c K}$ - mice were serum starved for 72 hours in DMEM/0.1\% serum and replated in $10 \%$ serum medium for the indicated time. Proteins $(40 \mu \mathrm{g})$ were resolved on SDS-PAGE, and membranes were probed with anti-p27 (C19) antibody; Grb2 levels were used as loading control. The graph shows the corresponding flow cytometry analysis of propidium iodide-stained serum-stimulated MEFs (average of 3 independent experiments \pm SEM). (B) Analysis of hepatocyte DNA content of Feulgen-stained liver sections in $p 27^{+/+}(n=11), p 27^{-/-}(n=5)$, $p 27^{C K-}(n=8)$, and $p 27^{S 1 O A / S 10 A}(n=4)$ mice. Error bars represent SD. Examples of $p 27^{+/+}$and $p 27^{C K-} \mathrm{H} \& \mathrm{E}$-stained liver sections illustrating nuclear size (original magnification, $\times 1,000$ ). (C) Multinucleated cells were counted on $3-\mu \mathrm{m}$-thick sections stained with $\beta$-catenin or $\mathrm{H} \& \mathrm{E}$ in a total of 1,000 hepatocytes from at least 3 different mice per genotype. The results were analyzed using 1-way ANOVA with the Tukey-Kramer multiple comparison test; ${ }^{* \star *} P<0.001$. Examples of $p 27^{+/+}$and $p 27^{C K-} \mathrm{H} \&$ E-stained liver sections illustrating multinucleation are shown (original magnification, $\times 1,000)$. (D) The percentage of multinucleated cells in kidney sections of $p 27^{+/+}(n=4)$ and $p 27^{C K-}(n=5)$ mice was determined. For each animal, 250-500 cells were counted. ${ }^{* \star} P<0.01$, Mann-Whitney $U$ test. Examples of $p 27^{+/+}$and $p 27^{c k-} \mathrm{H} \& \mathrm{E}-$ stained kidney sections illustrating multinucleation are shown (arrows) (original magnification, $\times 600$ ). Error bars in $\mathbf{C}$ and $\mathbf{D}$ represent SEM. 
A
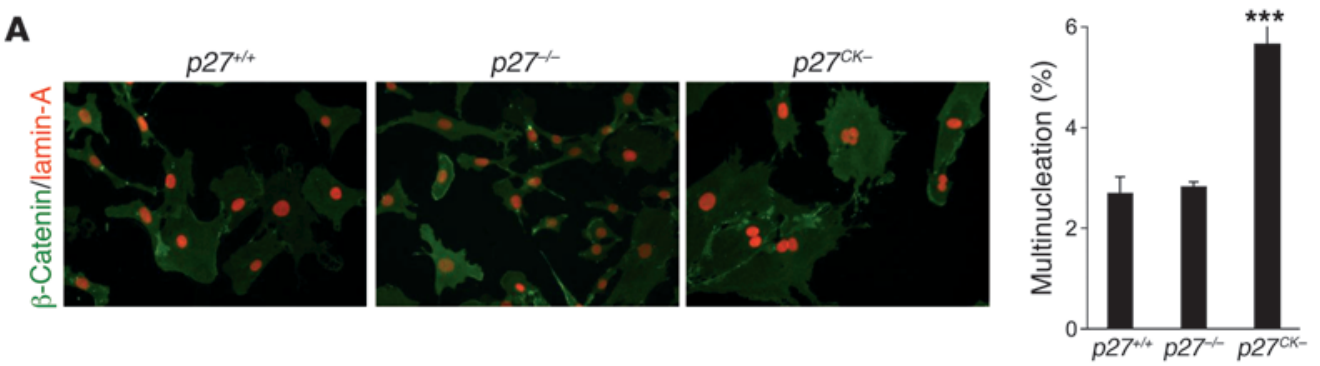

B
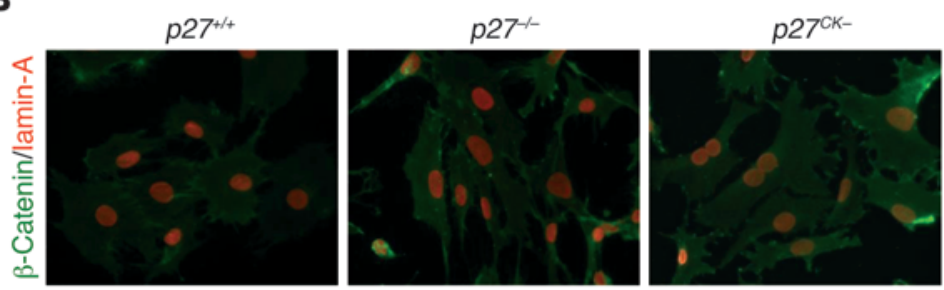

C
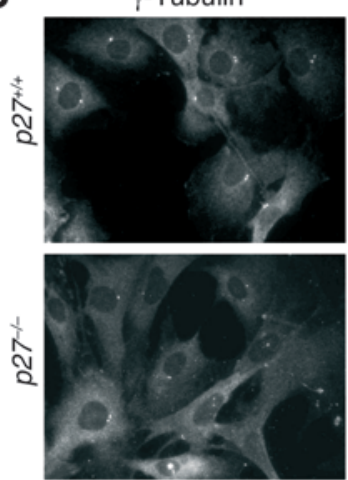

Hoechst/ $\gamma$-tubulin
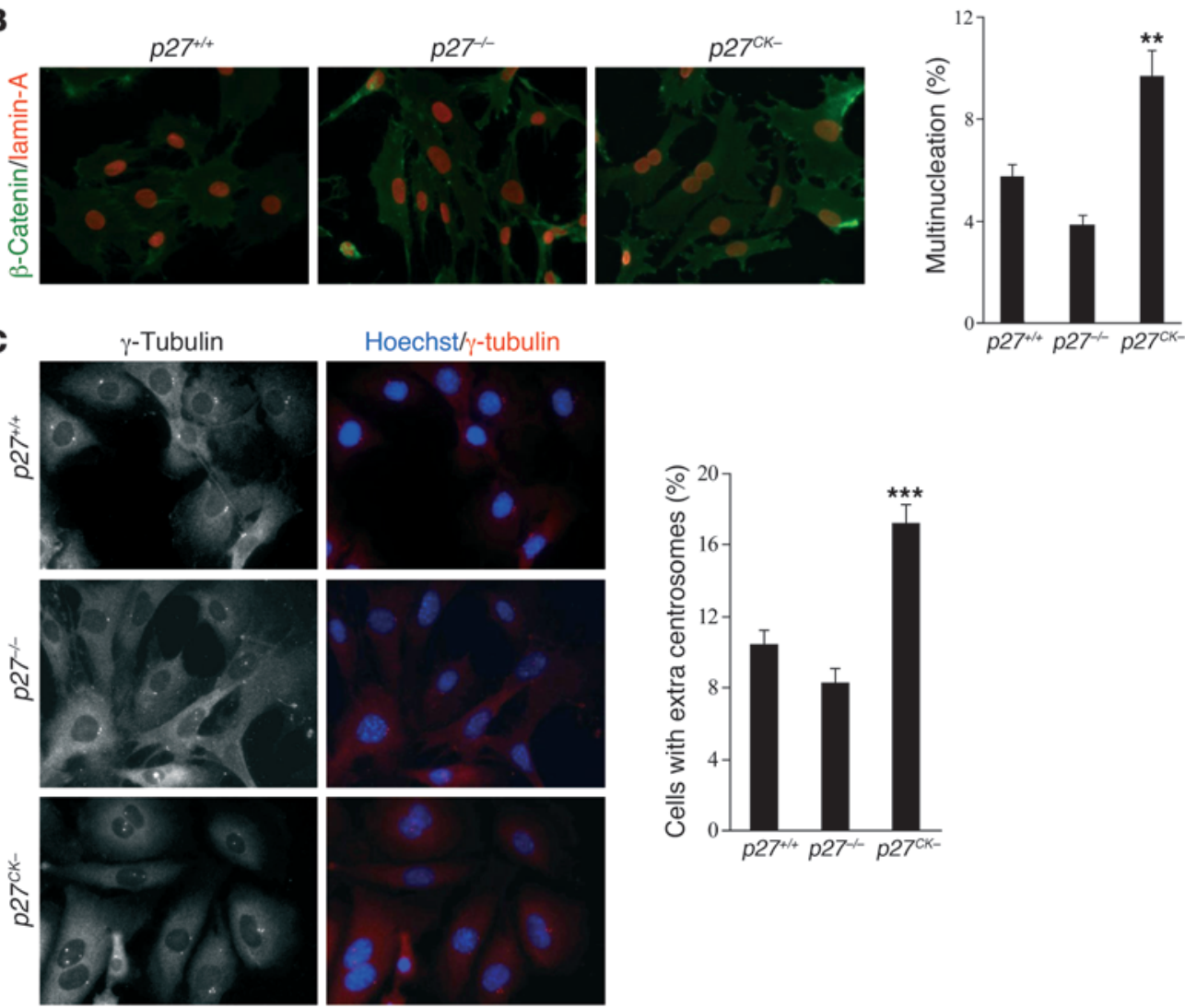

Figure 2

Multinucleation and centrosome amplification in p27cK- MEFs. (A) Primary MEFs (passages 2-3) derived from $p 27^{+/+}, p 27^{-/-}$, and $p 27^{C K-}$ mice were stained with anti- $\beta$-catenin and anti-lamin-A antibodies to visualize plasma membrane and nuclear envelope, respectively (original magnification, $\times 400$ ). For each experiment, 500 cells were counted per genotype. The graph shows the mean of 3 independent experiments. Results were analyzed by 1 -way ANOVA with the Tukey-Kramer multiple comparison test. $p 27^{+/+}$versus $p 27^{c K-}$, ${ }^{* * *} P<0.001$. (B) The number of nuclei per cell was counted in two lines of immortalized MEFs per genotype. Cells were stained as in A, and 500 cells per line were counted (original magnification, $\times 400$ ). The graph shows the average of 4 independent experiments. Statistical analyses were performed as in A. $p 27^{+/+}$versus p27ck-, ${ }^{* \star} P<0.01$. (C) Centrosomes were visualized by $\gamma$-tubulin staining and counted in 300 cells per genotype (original magnification, $\times 600$ ). Graph shows the average of 2 different MEF lines per genotype in 4 independent experiments. Statistical analyses were performed as in $\mathbf{A} ; p 27^{+/+}$versus $p 27^{C K-},{ }^{* \star *} P<0.001$. Error bars in $\mathbf{A}-\mathbf{C}$ represent SEM.

abscission, with a reopening of the intercellular bridge (Figure 3 , $\mathrm{D}-\mathrm{H}$, and Supplemental Videos 1-3). In some instances cytokinetic regression was rapid, while in others it was accompanied by a long delay (Figure 3, G and H, and Supplemental Videos 2 and 3). Quantification of the number of filmed cells becoming multinucleated due to intercellular bridge reopening revealed an increased

incidence in $p 27^{C K-}$ cells $(6.2 \%)$ compared with wild-type (3.9\%) and $p 27^{-/-}$cells $(1.7 \%)$ (Figure 3D). Interestingly, when the nature of the defect causing multinucleation (i.e., multinucleation due to bridge reopening as a percentage of the total number of multinucleated cells) was examined, we found that in both $p 27^{+/+}$ and $p 27^{C K-}$ MEFs, the majority of multinucleation events was caused by reopening of the intercellular bridge (Figure $3 \mathrm{E})$, while it represented less than $20 \%$ of the cause of multinucleation in $p 27^{-/-}$cells, which occurred predominantly via lack of ingression after anaphase or misplacement of the cleavage furrow. Thus, $p 27^{+/+}$and $\mathrm{p} 27^{\mathrm{CK}-}$ cells exhibited similar cytokinesis defects, but they arose at an increased incidence in $\mathrm{P} 27^{\mathrm{CK}-}$ MEFs. These results suggest that (a) this phenotype is a physiological role of p27 that becomes more frequent in p27 $7^{\text {CK- }}$ cells, possibly due to increased levels of the protein in $\mathrm{G}_{2} / \mathrm{M}$; and (b) that it is a cyclin-CDK-independent role of p27, since multinucleation in p27-null cells is caused by different defects. Overall, our data indicate that multinucleation caused by p27CK- arises from a cytokinetic abscission defect.

p27 interacts with citron-K. We recently identified the Rho effector citron-K as a potential p27-interacting protein in a mass spectrometry screen using P2 $7^{\mathrm{CK}-}$ as bait (Supplemental Table 1). Importantly, inhibition of citron-K by siRNA causes multinucleation in human and drosophila cells $(39-42,44,46)$ attributed to an abscission defect $(38,44)$. Citron-K expression was readily detected in mitotic and exponentially growing MEFs but was low in $\mathrm{G}_{0}$ and $\mathrm{G}_{1} / \mathrm{S}$ cells (Supplemental Figure $2 \mathrm{~A}$ ). In mitotic cells, citron-K localized at the zone of ingression in late anaphase and at the contractile ring and mid-body during telophase and cytokinesis (Supplemental Figure 2B), as previously reported. We confirmed the interaction of the two proteins by pull-down assays 

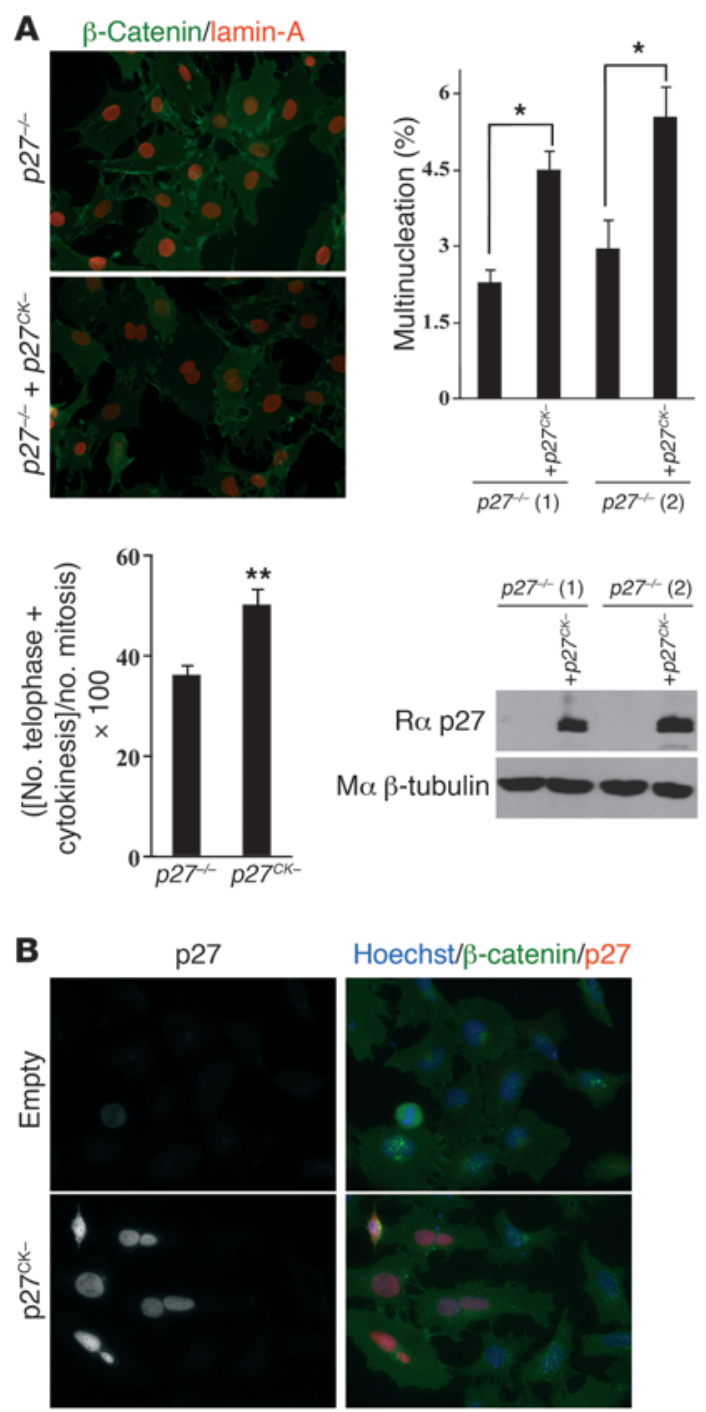

Hoechst/ $\beta$-catenin/p27
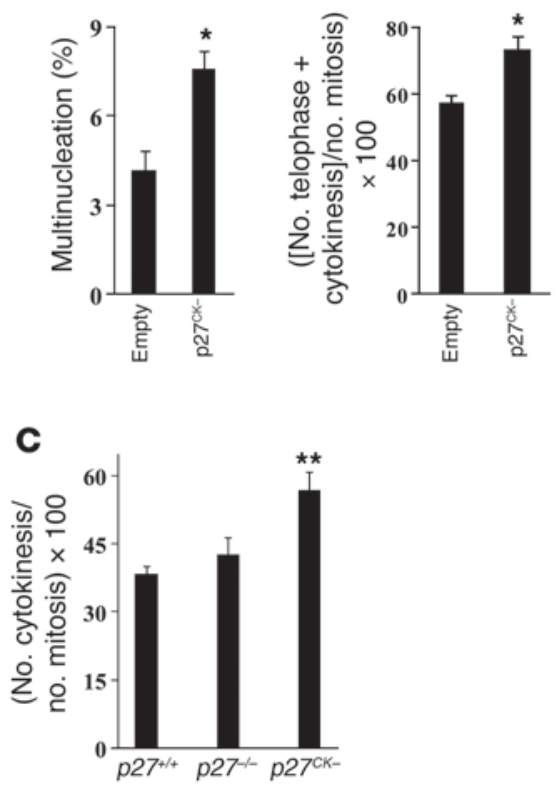
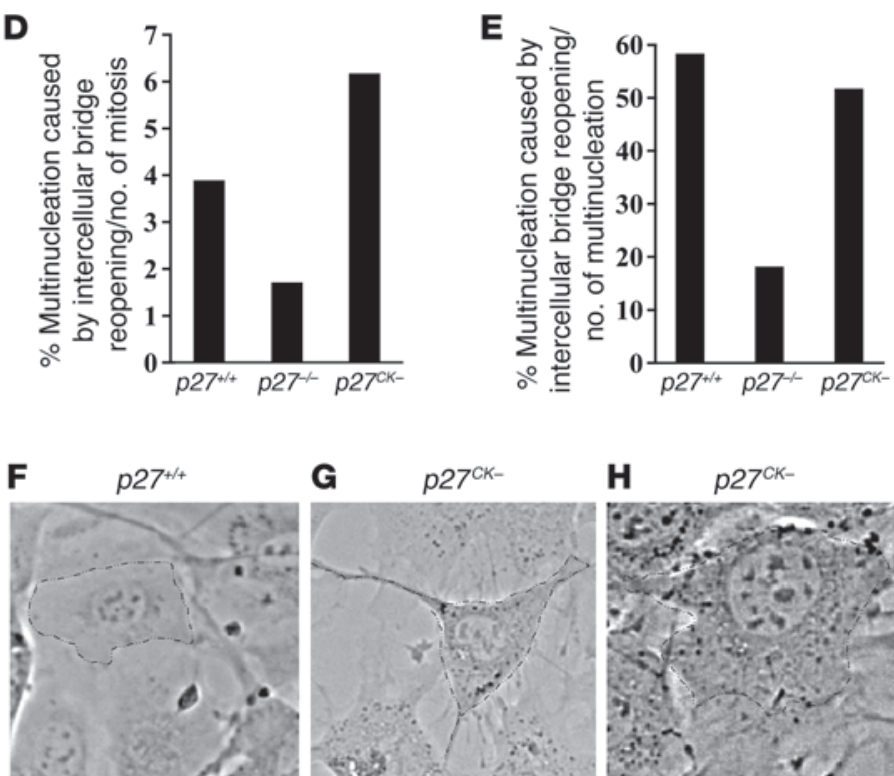

G $\quad p 27^{c k-}$
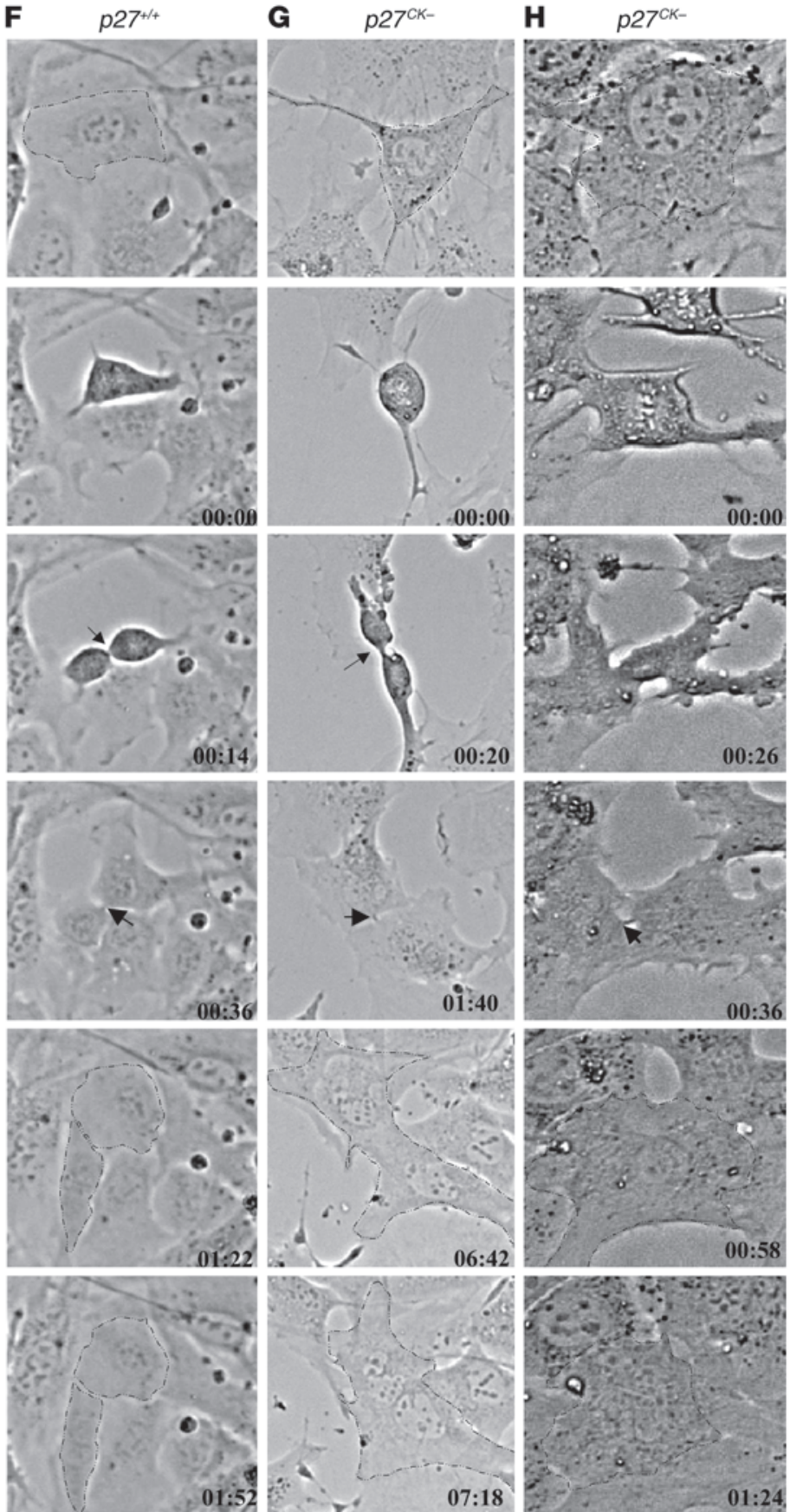


\section{Figure 3}

p27 CK- causes a cytokinesis defect. (A) Multinucleation was quantified ( 500 cells counted/line, $n=3$ ) in two lines of immortalized $p 27^{-/-}$MEFs infected or not with p27 ${ }^{\mathrm{CK}-}$ and stained for $\beta$-catenin and lamin-A (original magnification, $\times 400$ ). p27CK- levels following retroviral infection were measured by immunoblot for $p 27$, and $\beta$-tubulin levels were used as loading control. Lower graph: For each cell line, the proportion of mitotic cells in telophase and cytokinesis was determined in 50-100 mitotic figures; results are mean of 5 independent experiments. (B) Overexpression of p27cK- in HeLa cells causes multinucleation. HeLa cells were transfected with either empty vector or a vector encoding p27ck-. Transfected cells were visualized by $\mathrm{p} 27$ staining and colabeled for $\beta$-catenin, and 600 p27-positive cells were counted (original magnification, $\times 400$ ). Graphs show the average number of multinucleated cells in 3 independent experiments. Right graph: number of mitotic cells in telophase and cytokinesis observed in 100 mitotic figures $(n=4)$. In $\mathbf{A}$ and $\mathbf{B},{ }^{*} P<0.05,{ }^{* *} P<0.01$, Student's $t$ test. (C) Number of mitotic cells in cytokinesis in immortalized $p 27^{+/+}, p 27^{-/-}$, and p27ckMEFs. One hundred mitotic figures were counted per genotype in 3 independent experiments. Results were analyzed by 1-way ANOVA with the Tukey-Kramer multiple comparison test; $p 27^{+/+}$versus $p 27^{C K-}$, ${ }^{* \star} P<0.01$. Error bars in A-C represent SEM. (D-H) Videomicroscopy of $p 27^{+/+}, p 27^{-/-}$, and $p 27^{c k-}$ MEFs undergoing mitosis. (D) Incidence of multinucleation caused by cytokinetic regression relative to the total number of mitotic figures recorded $\left(p 27^{+/+}: n=181 ; p 27^{-/-}: n=117\right.$; p27ck-: $n=243$ ). (E) Nature of the defect causing multinucleation: multinucleation caused by reopening of the intercellular bridge as a percentage of the total number of multinucleation was determined for each genotype. (F-H) Examples of phase contrast videomicroscopy of mitotic $p 27^{+/+}(\mathbf{F})$ and $p 27^{C K-}$ MEFs $(\mathbf{G}$ and $\mathbf{H})$. Arrows indicate the intercellular bridge. In $p 27^{C K-}$, cells undergo mitosis normally until the formation of intercellular bridge, which regresses to form binucleated cells. Original magnification, $\times 200$.

in HEK293 cells overexpressing citron-K (Figure 4B) or a mutant (Cit- $\Delta \mathrm{N}$ ) lacking the $\mathrm{N}$-terminal kinase domain and part of the $\mathrm{CC}$ domain of citron-K (Figure 4C). The p27 interaction domain on citron-K was mapped using a series of deletion mutants representing the major domains of the protein (Figure 4A), and we found that p27 could interact with the CC domain of citron-K and also weakly with the RBD (Figure 4D). Interestingly, two regions in the CC domain of ROCK, RID (Rho interaction domain) and HR1 (homology region 1), participate with RBD in the binding of ROCK to RhoA (34). By sequence homology, we identified the corresponding regions in citron- $\mathrm{K}$ and generated another series of deletion mutants to identify the minimal binding region on citron-K that mediates binding to p27 (Figure 4A). In pull-down assays, the $15-\mathrm{kDa}$ region corresponding to the HR1 of citron-K was necessary for the interaction with p27 (Figure 4E and Supplemental Figure 3, B and C).

These results were validated by co-immunoprecipitation experiments (Figure 4, F-I). Citron-K was co-precipitated with p27 in HEK293 cells overexpressing both proteins (Figure 4F). Conversely, p27 co-precipitated with Cit- $\Delta \mathrm{N}$ using two different citron-K antibodies (Figure 4G). The interaction with the CC domain and the weaker interaction with the RBD were also observed by coimmunoprecipitation (Figure 4, H and I). Of note, the strongest interaction observed occurred when both HR1 and RBD were present (HR1-RBD mutant, Figure 4I), suggesting a synergistic effect in binding to $\mathrm{p} 27$. The interaction was confirmed on endogenous proteins, as citron-K was co-immunoprecipitated with p 27 from HeLa cells treated with either nocodazole or nocodazole plus purvalanol
A to enrich the population in mitotic and cytokinetic cells, with $54.3 \%(n=2)$ and $58.2 \%(n=2)$ of cells in $\mathrm{G}_{2}$ /M by flow cytometry, respectively (Figure $4 \mathrm{~J})$. No interaction could be detected in asynchronous populations of HeLa cells (data not shown), suggesting that this interaction takes place only in mitosis, consistent with the expression pattern of citron-K (Supplemental Figure 2A). Likewise, we were not able to confirm this interaction in MEFs, possibly because we cannot synchronize MEFs in $\mathrm{G}_{2} / \mathrm{M}$ above $30 \%-40 \%$ by serum stimulation, and MEFs undergo mitotic slippage after 5-6 hours in nocodazole, preventing efficient synchronization.

The citron-K-p27 interaction appears to be direct, since recombinant p27 interacted with GST-HR1-RBD beads (Figure 4K), as well as with GST-CC and GST-HR1 beads (Supplemental Figure 3D), but not with GST control beads. Finally, in pull-down assays with the $\mathrm{N}$ - or C-terminal halves of $\mathrm{p} 27$, we found that only the C-terminal part of p27 bound citron-K (Figure 4L) or Cit- $\Delta \mathrm{N}$ (Supplemental Figure $3 \mathrm{E}$ ). Together, our results indicate that the C-terminal half of $\mathrm{p} 27$ interacts with the HR1 domain of citron-K.

Localization of $p 27$ during mitosis. If $\mathrm{p} 27$ interacts with citron-K, one would expect both proteins to be present in the same subcellular structures, especially given the specific localization adopted by citron-K during mitosis (Supplemental Figure 2B and refs. 32, 37). Interestingly, p27 was identified as one of the proteins present at the mid-body in a proteomic screen (53). In order to decrease nonspecific background and remove soluble p27, we permeabilized cells prior to fixation and immunofluorescence staining. In these conditions, during cytokinesis we detected both p27 and citron-K at the mid-body (Figure 5A) and contractile ring (Figure 5B) in HeLa cells. As expected, RhoA was present at the plasma membrane and the mid-body, where it colocalized with p27 and citron-K (Figure 5C). In primary MEFs, p27 localized at the mid-body in $p 27^{+/+}$and $\mathrm{p} 27^{\mathrm{CK}-}$ MEFs undergoing cytokinesis, while no signal was detected in $p 27^{-/-}$MEFs (Figure 5D). We confirmed this localization using HeLa cells transfected with GFP-p27 or GFP-p27cKfusion proteins and monitoring of GFP fluorescence (Supplemental Figure 4A). Finally, examination of HeLa cells at different phases of mitosis revealed that p27 first appeared on the central spindle in late anaphase, was present on the contractile ring during telophase, and remained at the mid-body at the end of cytokinesis (Supplemental Figure 4B). Consistent with the idea of a mitosisspecific interaction between $\mathrm{p} 27$ and citron-K, p27 localization at the mid-body was lost upon return of the cells to interphase, while citron-K was still detected at the mid-body remnant (or mid-body derivative) in HeLa cells and MEFs (Supplemental Figure 5 and ref. 54). Overall, our data indicate that citron-K and p27 colocalize at the contractile ring and mid-body during cytokinesis.

p27 ${ }^{C K-}$ interferes with citron-K function. A distinct possibility is that $\mathrm{p} 27^{\mathrm{CK}-}$ may cause cytokinetic failure by interfering with citron-K function. To understand the functional relationship between $\mathrm{p} 27$ and citron-K, we examined the effect of $\mathrm{p}^{27^{\mathrm{CK}-}}$ expression in $\mathrm{HeLa}$ cells treated with citron-K siRNAs. The efficiency of the siRNA treatment was evaluated by Western blot (Figure 6A). As reported previously, reduction of citron-K levels by siRNA causes multinucleation $(39-42,44,46)$. This phenotype was not significantly

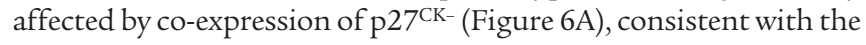
idea that $\mathrm{p} 27$ and citron-K function in the same pathway.

On the other hand, expression of either the HR1 or HR1-RBD domain prevented the multinucleation phenotype caused by p27 ${ }^{\mathrm{CK}-}$ expression in HeLa cells (Figure 6B). Similarly, introduction of the HR1 domain in p $^{2 \mathrm{CK}-}$ primary MEFs was sufficient 
A

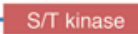

$\mathrm{CC}$

RBD Zn-F, PH CNH - Pro- $\mathrm{CDZ}$ - 2055

Deletion mutants generated
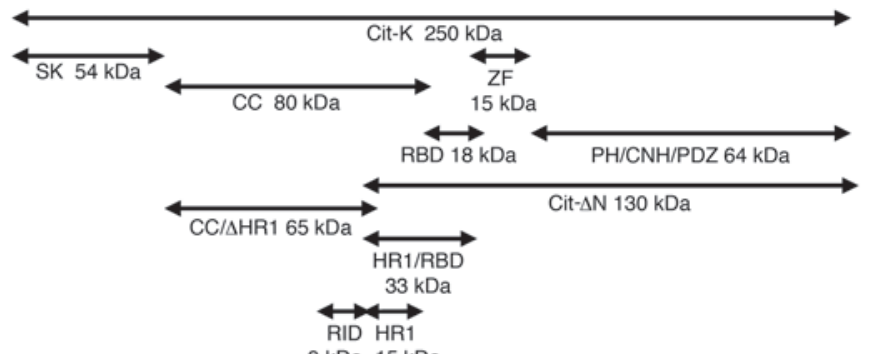

$9 \mathrm{kDa} 15 \mathrm{kDa}$
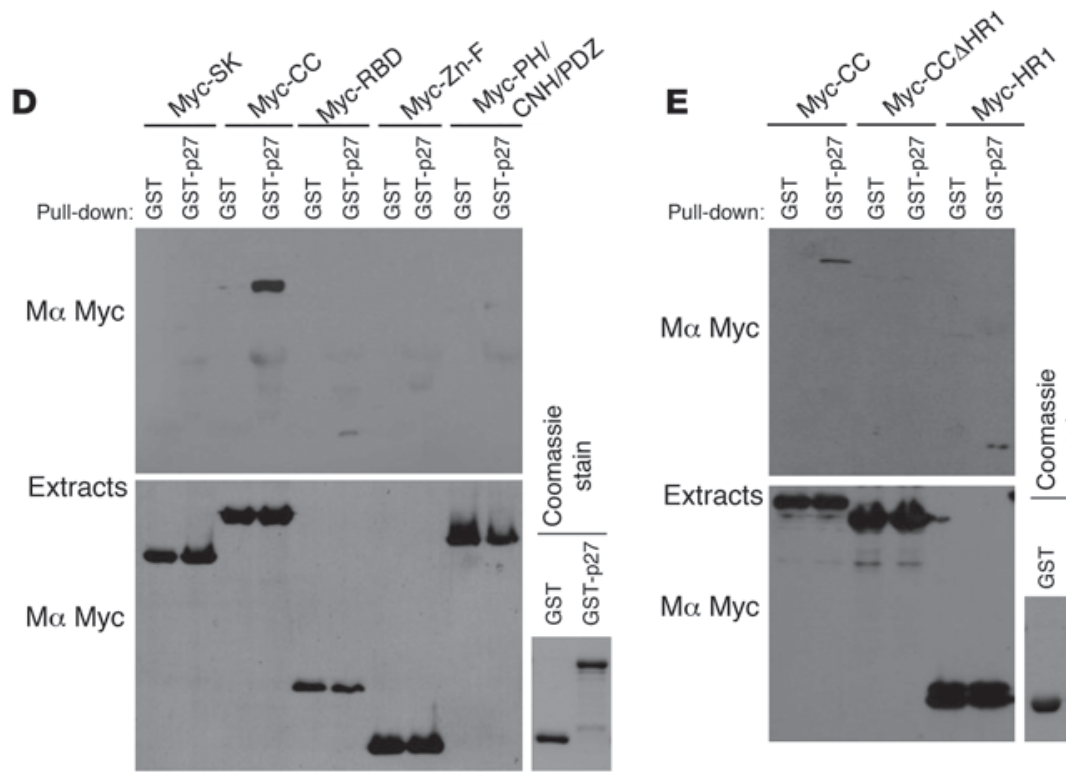

H

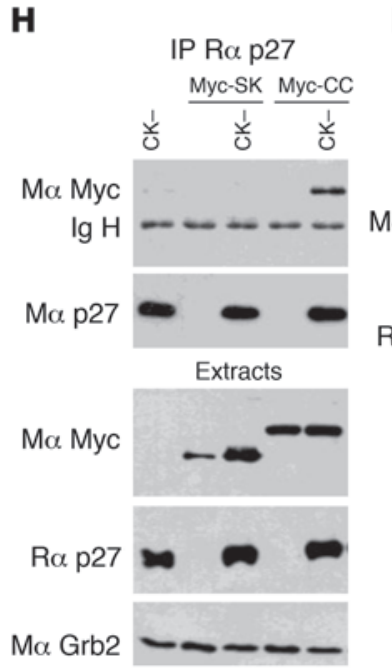

I
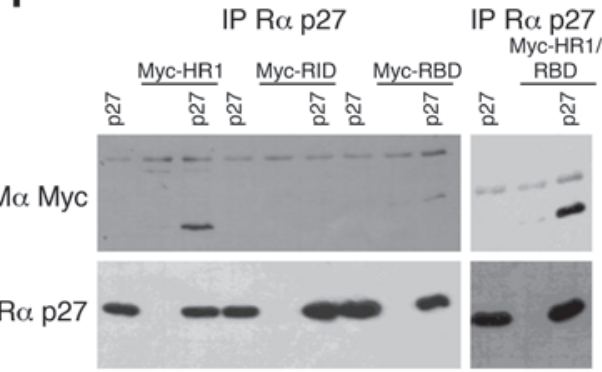

Extracts

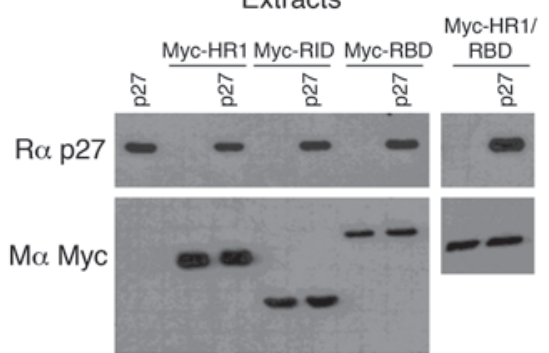

B

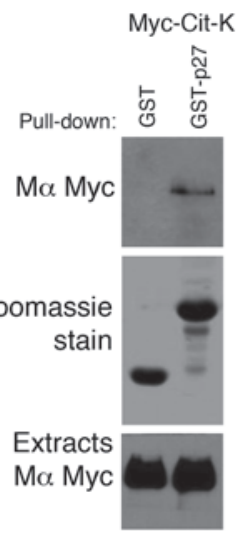

C

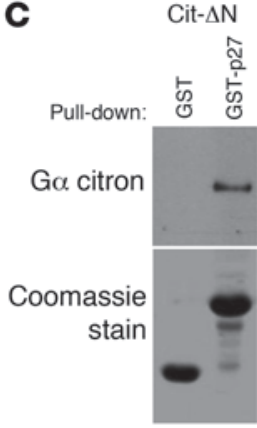

Extracts

$\mathrm{G} \alpha$ citron
$\mathbf{F}$

F IP R $\alpha$ p27

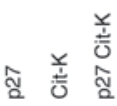

Ga citron

.

$\mathrm{M} \alpha \mathrm{p} 27$

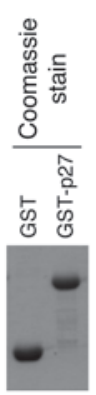

$\mathrm{R} \alpha \mathrm{p} 27$

Extracts

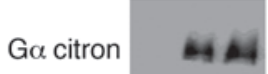

Ma Grb2

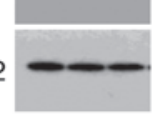

G IP G $\alpha$ citron $\mathrm{C} 20$

G ลิญ สิ้

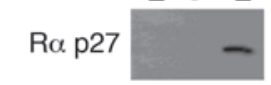

Ga citron

IP G $\alpha$ citron S20

$R \propto \mathrm{p} 27$

G $\alpha$ citron

Extra
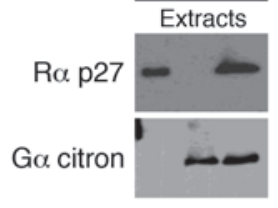

$\mathbf{K}$

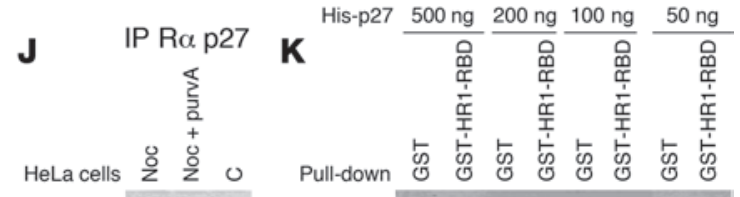

$\mathrm{M} \alpha$ citron -

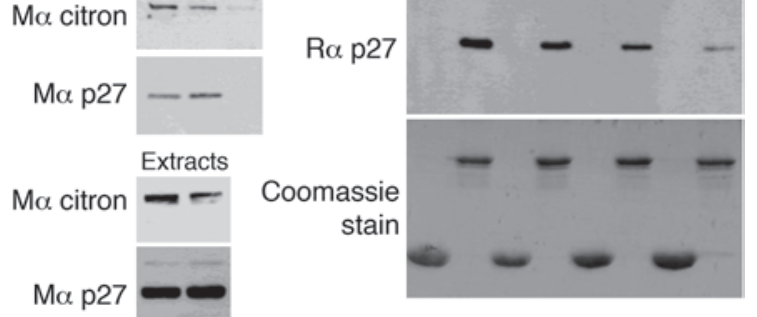

$\mathrm{M} \alpha \mathrm{p} 27$

$\mathbf{L}$

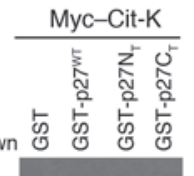

M $\alpha$ Myc

Coomassie stain

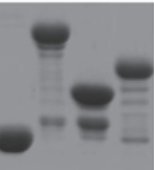

Extracts

$\mathrm{M} \alpha \mathrm{Myc}$ 


\section{Figure 4}

The C-terminal half of p27 interacts with the HR1 domain of citron-K. (A) Schematic representation of citron-K (Cit-K) and deletion mutants. All constructs except the Cit- $\Delta \mathrm{N}$ mutant contain an $\mathrm{N}$-terminal Myc epitope tag. S/T kinase, Ser/Thr kinase domain; CC, CC domain; Zn-F, $\mathrm{Zn}$ finger; $\mathrm{PH}$, pleckstrin homology; $\mathrm{CNH}$, citron homology; Pro-rich, proline-rich region: PDZ, PDZ binding domain. (B-E) HEK293 cells transfected with citron-K or the indicated deletion mutant were subjected to pull-down assays using GST or GST-p27 beads. The amounts of citron-K or deletion mutant bound to the beads and of transfected protein present in the extracts were detected by immunoblot using the indicated antibodies ( $\mathrm{M} \alpha$, mouse anti-; $\mathrm{G} \alpha$, goat anti-; R $\alpha$, rabbit anti-). The amount of GST or GST-p27 used in the assays was visualized by Coomassie staining. (B and C) p27 interacts with citron-K. (D) p27 interacts with the $\mathrm{CC}$ domain of citron-K and more weakly with the RBD domain. (E) The HR1 domain present in the CC domain is necessary for $\mathrm{p} 27$ interaction. $(\mathbf{F}-\mathbf{I})$ Co-immunoprecipitations using rabbit anti-p27 (C19) (F, H, and I) or two different goat anti-citron antibodies (C20 or S20) (G). Co-immunoprecipitated proteins were detected by immunoblot with the indicated antibodies. The immunoprecipitated proteins were visualized by reprobing for mouse anti-p27 (F8) (F, H, and I) or goat anti-citron (C20) (G). Immunoblots of extracts show the level of transfected proteins in each condition. Grb2 levels were used as loading control. ( $\mathbf{F}$ and $\mathbf{G})$ p27 interacts with citron-K in vivo. ( $\mathbf{H}$ and $\mathbf{I}$ ) p27 interacts with all mutants containing the HR1 domain. A weaker interaction is also seen with the RBD. (J) p27 interacts with citron-K in HeLa cells. Endogenous p27 was immunoprecipitated using rabbit anti-p27 (C19) in HeLa cells. The co-immunoprecipitated citron-K was visualized using mouse anti-citron-K antibody. Endogenous levels of each protein are shown in the lower panels. Noc, nocodazole; purvA, purvalanol A; C, control. (K) p27 interacts with citron-K directly. Different amounts of recombinant His-p27 were used in pull-down assays with GST or GST-HR1-RBD beads. Immunoblot show the amount of p27 bound to the beads. The amount of GST or GST-HR1-RBD used in the assay was visualized by Coomassie staining. (L) The C-terminal half of p27 interacts with citron-K. Pull-downs were realized as in B with GST-p27WT, GST-p27N $\mathrm{N}_{\mathrm{T}}$ (N-terminal, aa 1-86), and GST-p27C (C terminal, aa 87-198).

to rescue the multinucleation phenotype observed in these cells to wild-type levels (Figure 6C and Figure 2A). These results suggest that $\mathrm{p} 27^{\mathrm{CK}-}$ binds to ectopic HR1 and can no longer interfere with endogenous citron-K. Overall, these rescue experiments functionally validate the interaction results and suggest that p27 CK- causes multinucleation by directly interfering with citron$\mathrm{K}$ function. To ascertain that the phenotype caused by $\mathrm{p} 27^{\mathrm{CK}-}$ was not due to inhibition of RhoA by p27, we monitored the effect of

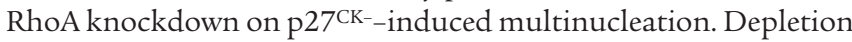
of RhoA with siRNA did not cause multinucleation, as reported by others $(40,55)$, and importantly did not affect that caused by p27 CK- expression (Figure 6D).

p27 competes with Rho for binding to citron-K. To identify the mechanism by which $\mathrm{p} 27$ interferes with citron-K function, we first tested whether p27 could inhibit citron-K's kinase activity. p27 was recently reported to inhibit the activity of casein kinase-2, thus providing evidence that it may inhibit kinases other than CDKs (56). However, in in vitro kinase assays, increasing amounts of recombinant p27 did not affect the activity of citron-K against either histone $\mathrm{H} 1$ or MRLC2 as substrate, while it potently inhibited CDK2-associated activity, as expected (Supplemental Figure 6).

The CC domain of citron-K, within which p27 binds, has been reported to mediate oligomerization in citron-N (57). However, p27 had no effect on the ability of citron-K or mutants contain- ing the CC domain to form homo-oligomers (data not shown). The CC domain also includes the RBD, RID, and HR1 regions involved in binding to Rho proteins $(32,34)$. Thus, a possibility is that by binding to HR1, p27 interferes with the ability of citron-K to interact with Rho. p27 also binds to Rho (10), and we measured the RhoA-p27 interaction in the presence of Cit- $\Delta \mathrm{N}$. In absence of Cit- $\Delta \mathrm{N}$, a clear interaction was detected between RhoA and p27 (Figure 7A), as reported previously (10, 58-60). However, the $\mathrm{p} 27-\mathrm{RhoA}$ interaction was greatly diminished in the presence of Cit- $\Delta \mathrm{N}$, suggesting that the three proteins cannot exist in the same complex and compete for binding to one another (Figure $7 \mathrm{~A})$. Conversely, the interaction of citron- $\mathrm{K}$ with another activator, RhoB, was nearly abolished in the presence of $\mathrm{p} 27$ or $\mathrm{p} 27^{\mathrm{CK}-}$ (Figure 7B). Similarly, interaction of the HR1-RBD domain with RhoA was also decreased in the presence of p27 (Figure 7C). On the other hand, the binding of the RBD domain of citron-K to RhoA was only partially affected by $\mathrm{p} 27$, consistent with the fact that $\mathrm{p} 27$ shows a stronger interaction with the HR1 domain than with the RBD domain of citron-K (Figure 7D). Together, our data suggest that $\mathrm{p} 27$ can interfere with the binding of citron- $\mathrm{K}$ to its activators, the Rho-GTPases.

Interestingly, Larrea et al. recently reported that binding to RhoA was promoted by phosphorylation of p27 on Thr198 (58). Thus, an attractive hypothesis is that another post-translational modification (or lack thereof) may target p27 for binding to citron-K. p27 binds citron-K via its $C$ terminus half (Figure $4 \mathrm{~L}$ ), and we narrowed down the citron-K interaction domain to the last 8 aa of $\mathrm{p} 27$, as a p27CK- 1-190 mutant did not bind citron-K (Figure 7E). Also, mutation of Thr198 of p27 into Asp (T198D) or Glu (T198E), which mimicked a phosphorylation event, abolished binding of p27 to citron-K, whereas with a non-phosphorylatable mutation to Ala (T198A), p27 could still interact with citron-K (Figure 7E). A p27 1-197 mutant could still bind citron-K (data not shown), indicating that aa 191-197 of p27 are critical for this interaction. Thus, while $\mathrm{p} 27$ binding to RhoA is facilitated by phosphorylation on Thr198 (58), citron-K only bound the non-phosphorylated form of p27. Next we tested the ability of these mutants of p27cK- to induce multinucleation in HeLa cells (Figure 7F) and $p 27^{-1-}$ MEFs (Figure 7G). p27CK- T198A, which binds citron-K, was as potent as $27^{\mathrm{CK}-}$ in causing multinucleation, while the $\mathrm{p} 27^{\mathrm{CK}-} \mathrm{T} 198 \mathrm{E}$, T198D, and 1-190 mutants, which do not bind citron-K, did not, thus confirming that $\mathrm{p} 27^{\mathrm{CK}-}$ indeed requires citron-K binding to induce multinucleation.

\section{Discussion}

In the present report, we provide evidence suggesting that p27 plays a role during mitosis that is independent of cyclin-CDK regulation. This role was revealed in p $^{27^{\mathrm{CK}-}}$ knock-in mice, in which p27 cannot bind cyclin-CDKs: these mice exhibited a phenotype of multinucleation and polyploidy in several cell types. Our data suggest that p27 may control cytokinesis via the regulation of citron-K activation. Indeed, we found that p27 and p27CK- could directly bind citron- $\mathrm{K}$, thereby preventing its interaction with its activators, the Rho GTPases.

Although the phenotype of $\mathrm{p}^{27^{C K-}}$ mice is reminiscent of that observed in $S k p 2^{-1-}$ animals, several differences suggest that they are independent from one another. Skp2-null mice develop a phenotype of polyploidy and centrosome amplification in the liver, kidney, pancreas, lung, and MEFs; these phenotypes are completely rescued by the concomitant deletion of $\mathrm{p} 27$, thus 
HeLa cells A

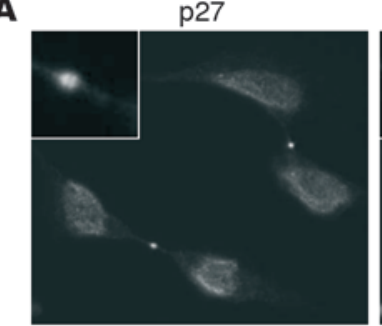

B

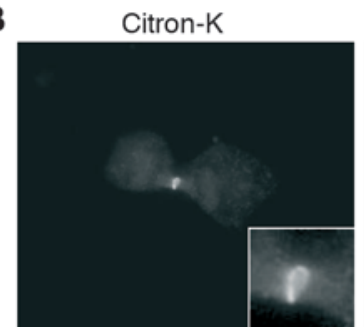

C

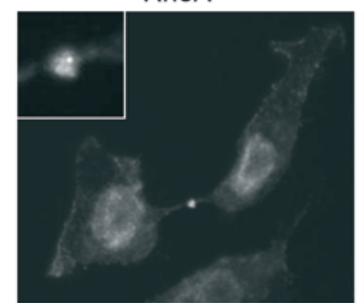

MEFs

D
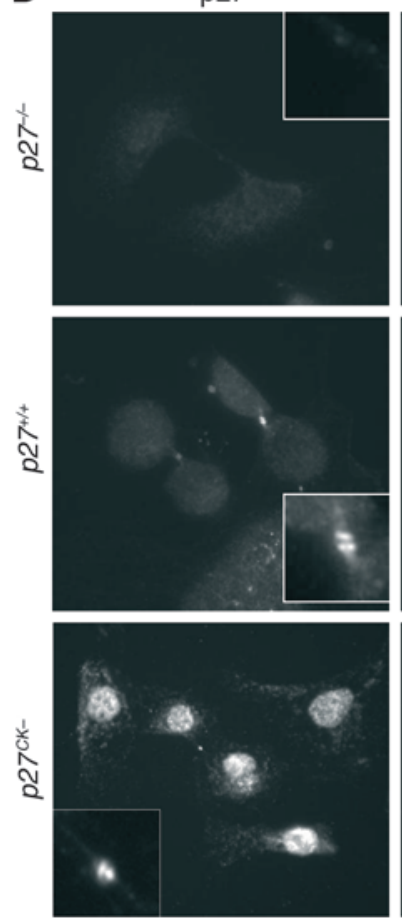

Citron-K

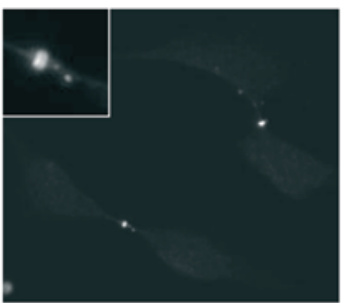

p27

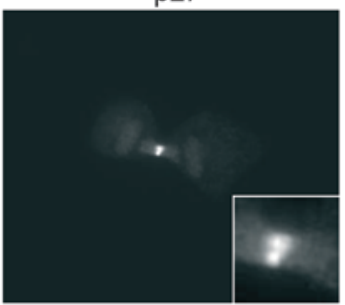

p27

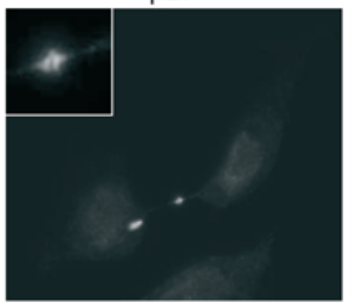

Citron-K
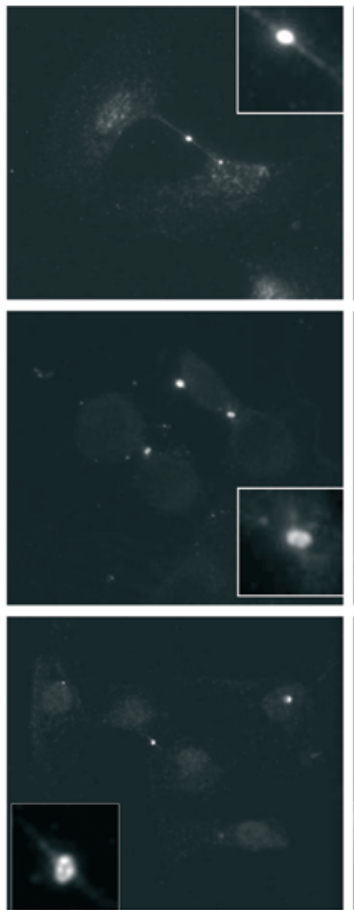

$\beta$-Tubulin

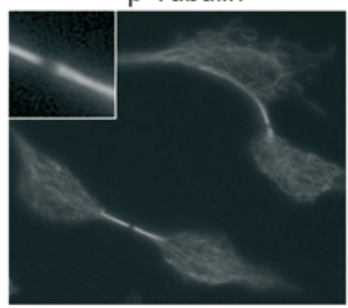

$\beta$-Tubulin

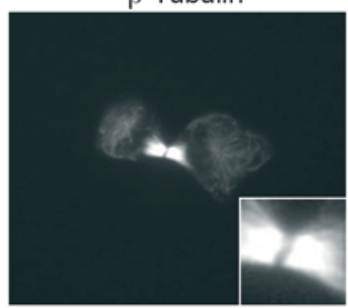

Citron-K

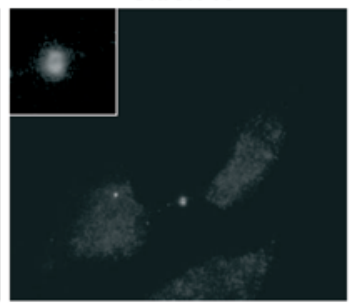

$\beta$-Tubulin
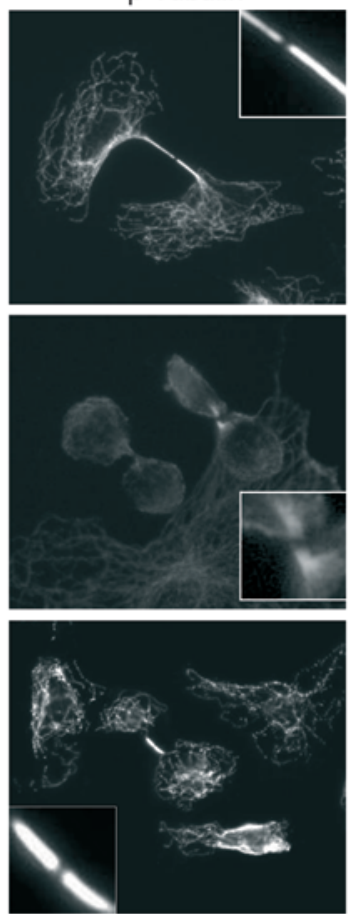

p27/citron-K/3-tubulin

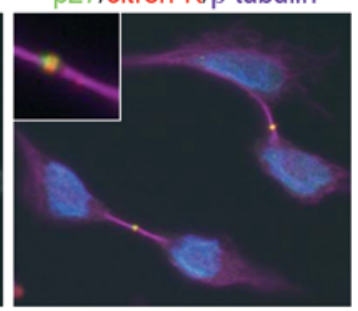

Citron-K/p27//-tubulin

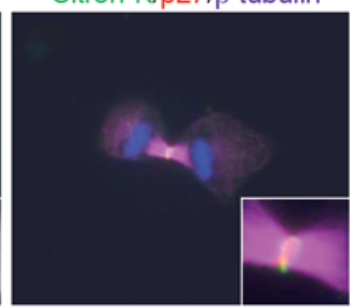

RhoA/p27/citron-K

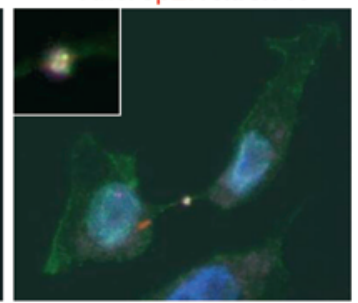

p27/citron-K/ $\beta$-tubulin
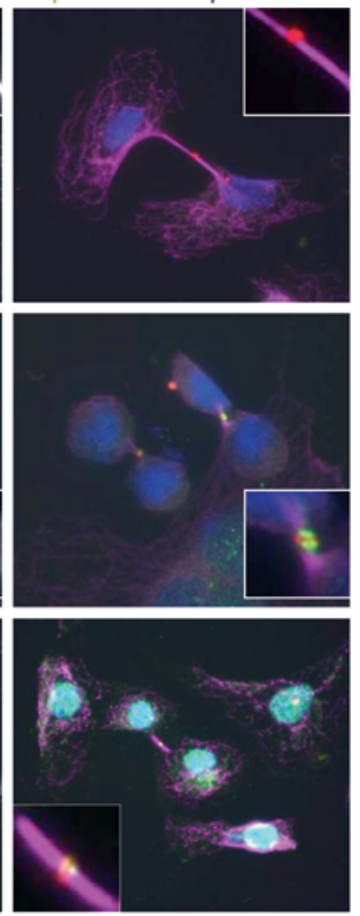

Figure 5

Colocalization of p27 and citron-K at the mid-body. (A and B) After 24 hours in culture, HeLa cells were permeabilized with digitonin (40 $\mu \mathrm{g} / \mathrm{ml}$ ) before fixation. Mid-bodies were visualized with citron-K (goat anti-citron C20) staining in red (A) or green (B); p27 was detected with rabbit antip27 (C19) antibody in green (A) or red (B); and microtubules were stained with mouse anti- $\beta$-tubulin (purple) (original magnification, $\times 600)$. (C) HeLa cells were permeabilized with digitonin prior to fixation and stained with mouse anti-RhoA (26C4) antibody (green), rabbit anti-p27 (C19) (red), and goat anti-citron (C20) (purple) (original magnification, $\times 600$ ). (D) Primary MEFs derived from p27 $7^{+/+}, \mathrm{p} 27^{-/-}$, and p27ck- mice were stained with anti-p27 (C19), anti-citron (C20), and anti- $\beta$-tubulin after digitonin permeabilization and fixation (original magnification, $\times 600)$. 
A

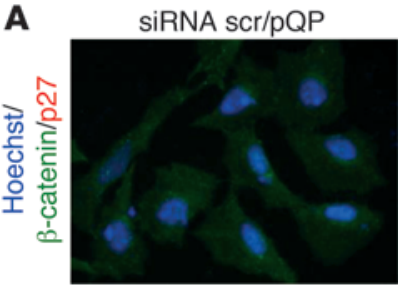

siRNA scr/pQP p27ck-

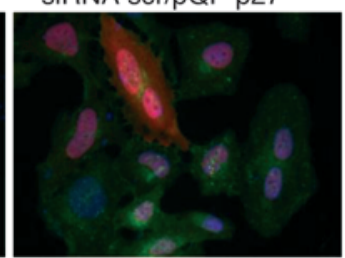

siRNA citron/pQP p27 ${ }^{\text {ck- }}$
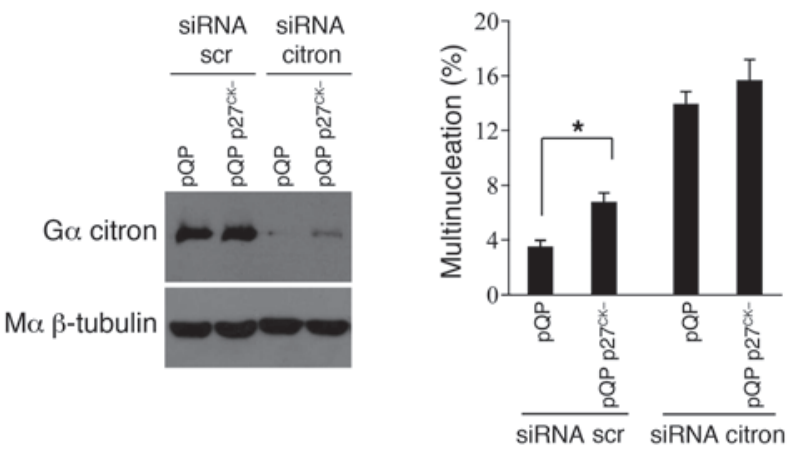

B

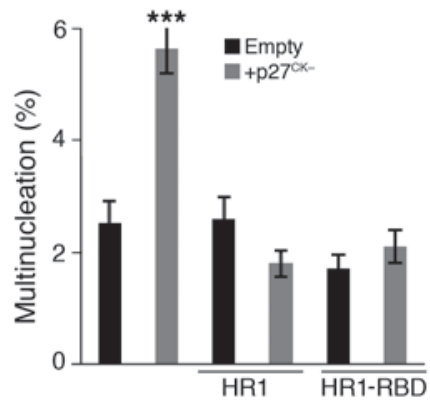

C

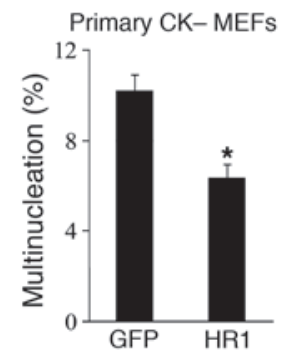

D

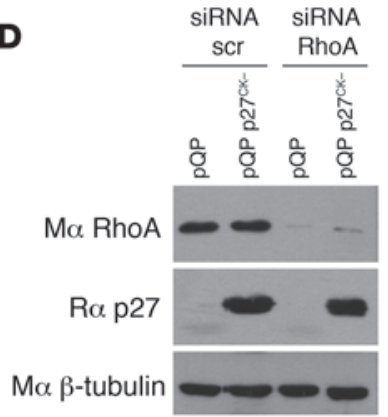

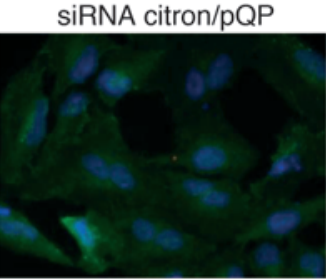

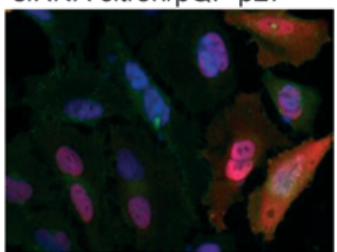

Figure 6

p27 CK- interferes with citron-K function. (A) p27 ${ }^{\mathrm{CK}-}$ does not affect the multinucleation caused by citron-K depletion. HeLa cells were transfected with scrambled (scr) or citron-K siRNAs and plasmids expressing p27CK- or empty vector (pQP). Citron-K knockdown was controlled by immunoblotting with goat anti-citron antibodies; $\beta$-tubulin levels were used as loading control. Multinucleation was quantified in cells (500 cells/condition, $n=3$ ) stained with $\beta$-catenin and p27 antibodies and Hoechst (original magnification, $\times 400$ ). Results were analyzed using 1 -way ANOVA with the Tukey-Kramer multiple comparison test; ${ }^{*} P<0.05$. (B) The minimal p27-binding domain of citron-K (HR1) rescues the multinucleation caused by p27CK- overexpression. HeLa cells were transfected with p27CK- and/or different domains of citron-K. Multinucleation was quantified (500 cells/condition, $n=3$ ). Results were analyzed by 1 -way ANOVA with the Newman-Keuls test; ${ }^{* * *} P<0.001$. (C) The HR1 domain rescues the multinucleation in $p 27^{C K}$ - primary MEFs. $p 27^{C K}$ - primary MEFs were transfected with GFP or with the HR1 domain, and multinucleation was evaluated 48 hours later (350-600 cells/condition, $n=3$ ). Results were analyzed using Student's $t$ test; * $P<0.05$. (D) RhoA depletion has no effect on p27 CK--induced multinucleation. HeLa cells were transfected with scrambled or RhoA siRNA and plasmids expressing p27CK- or empty vector (pQP). RhoA knockdown and p27 expression were controlled by immunoblotting with anti-RhoA and anti-p27 antibodies; $\beta$-tubulin levels were used as loading control. Multinucleation was quantified (500 cells/condition, $n=3$ ). Results were analyzed as in $\mathbf{A} ;{ }^{*} P<0.05,{ }^{\star \star} P<0.01$. (A-D) Error bars represent SEM.

proving the direct involvement of $\mathrm{p} 27$ in this process (19-21, 61). Elevated levels of p27 in $\mathrm{S}$ and $\mathrm{G}_{2} / \mathrm{M}$ phases, due to the lack of Skp2-mediated degradation, cause a failure to enter mitosis via either inhibition of CDK1 activity or inhibition of cyclin A expression $(20,21)$. Thus, in $S k p 2^{-/-}$mice, the mechanism seems more akin to an endoreplication cycle, with cells skipping $M$ phase. Although p27 ${ }^{\mathrm{CK}-}$ levels are also elevated during the $\mathrm{S}, \mathrm{G}_{2}$, and $\mathrm{M}$ phases of the cell cycle, p27 ${ }^{\mathrm{CK}-}$ does not bind or inhibit cyclinCDK complexes $(14,15)$. Moreover, the phenotype of multinucleation observed in $p 27^{C K-}$ livers, kidneys, and MEFs has not been reported in Skp2-1- animals, suggesting that another mechanism is at play in ${ }^{27^{C K-}}$ mice. Indeed, we found that $p 27^{C K-}$ cells enter and progress through mitosis normally but exhibit a delay at the end of cytokinesis and sometimes fail to undergo abscission, resulting in binucleated cells. Interestingly, in the liver, diploid hepatocytes go through a first acytokinetic division, resulting in a single cell with two diploid nuclei, and then through normal mitosis that results in two cells with one tetraploid nucleus (62). Thus, it is possible that the increased polyploidy observed in the liver of $\mathrm{p} 27^{\mathrm{CK}-}$ mice is merely a consequence of the increase in the number of binucleated cells undergoing normal mitosis. It is also likely that centrosome amplification in $\mathrm{p}^{27^{C K-}}$ MEFs is a consequence of mitotic failure and is not due to an aberrant centrosome replication cycle. 
A

IP Ma Myc (RhoA63L)

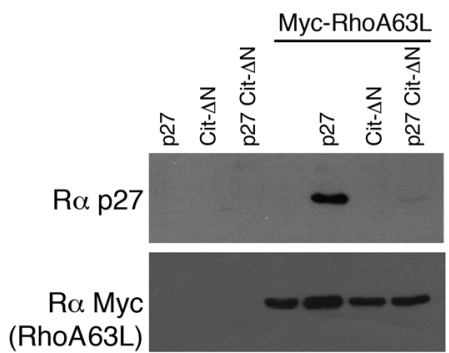

Extracts

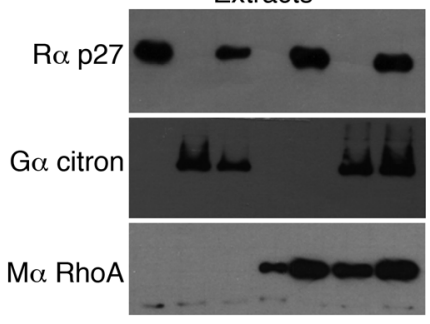

B

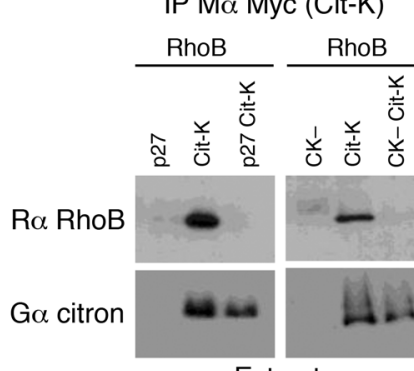

Extracts

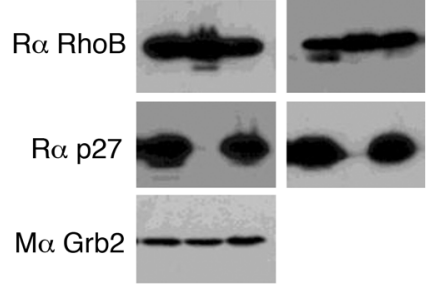

C IP R $\propto$ Myc (HR1-RBD) D

D

IP R $\propto$ Myc (RBD)

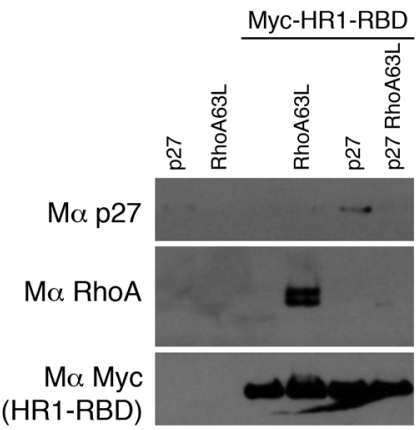

Extracts Myc-HR1-RBD

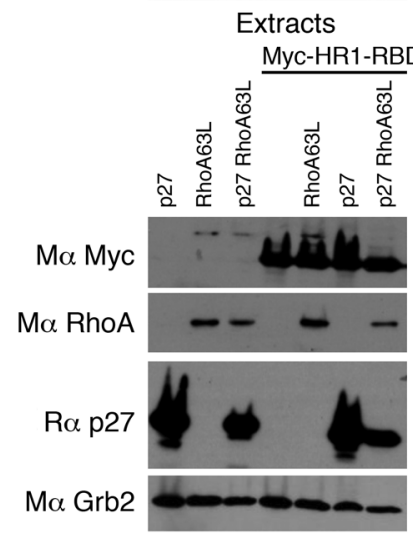

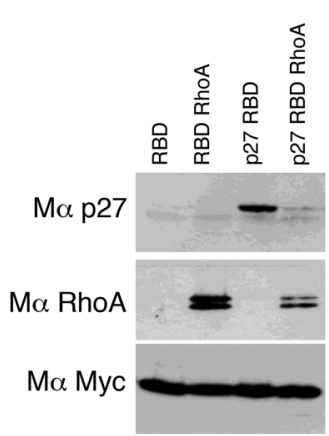

Extracts

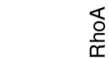

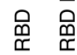

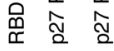

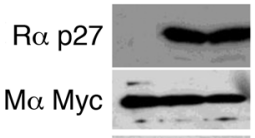

Ma RhoA
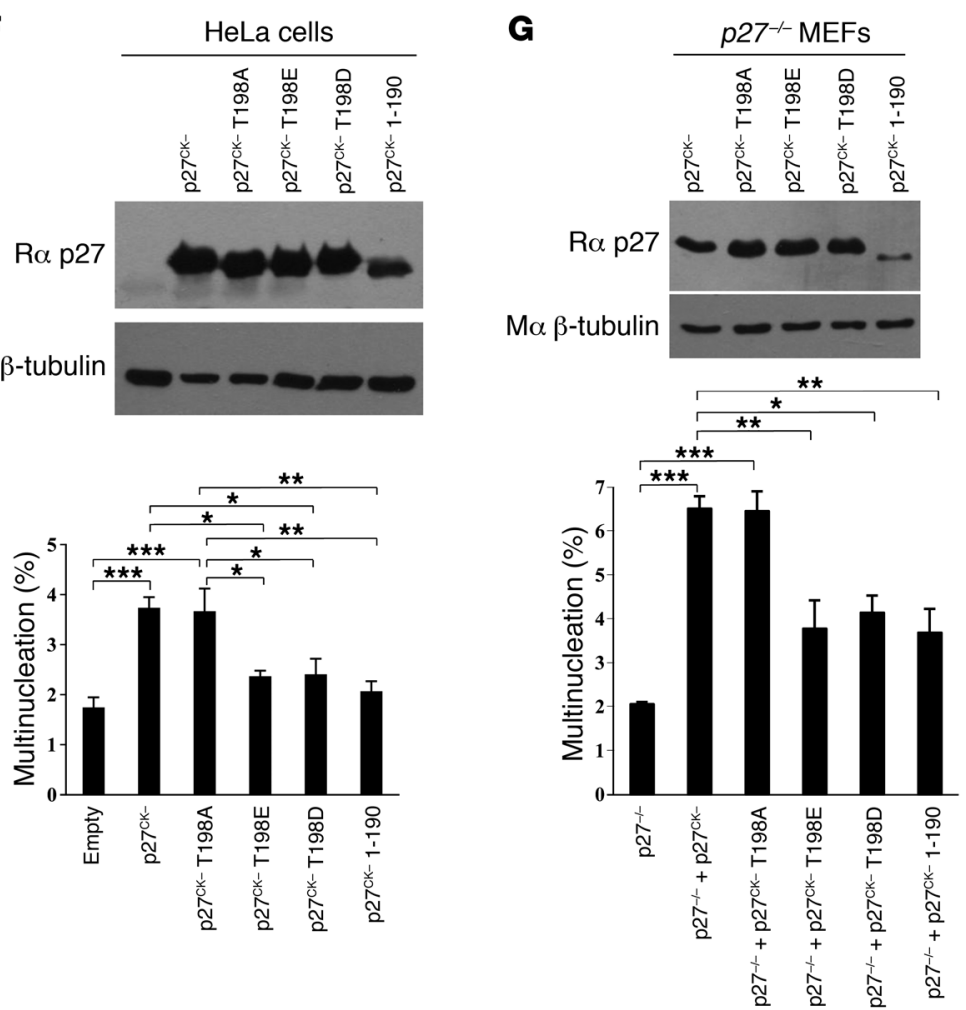

E

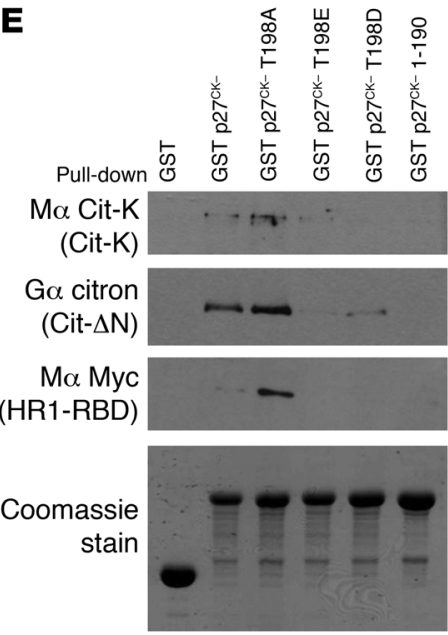

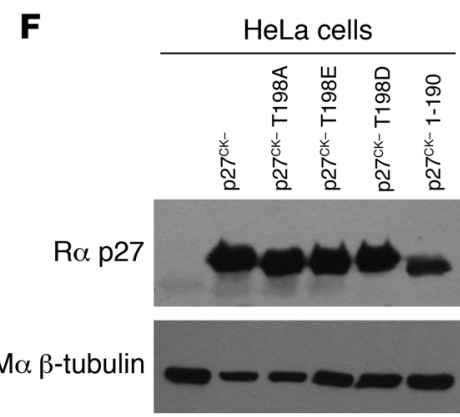

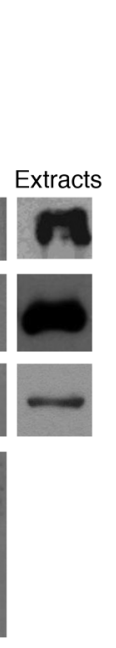




\section{Figure 7}

p27cK- interferes with Rho-citron-K interaction. (A) HEK293 cells were transfected with p27, Myc-RhoA63L, and/or Cit- $\Delta \mathrm{N}$. RhoA63L was immunoprecipitated with mouse anti-Myc (9E10) antibodies. The amount of $\mathrm{p} 27 \mathrm{co}$-immunoprecipitated was determined by probing with rabbit anti-p27 (C19). Immunoprecipitated RhoA63L was visualized by reprobing with rabbit anti-Myc (A14). The amount of transfected proteins present in cell extracts is shown in the lower panels. (B) HEK293 cells were transfected with p27 or p27 ${ }^{\mathrm{CK}-}$, RhoB, and/or Myc-citron-K. Citron-K was immunoprecipitated using mouse anti-Myc (9E10). The amount of RhoB bound to citron-K was determined by probing with anti-RhoB (119) antibodies. After stripping, membranes were reprobed with goat anti-citron (C20). Amounts of transfected proteins are shown in the lower panels. (C and D) HEK293 cells were transfected or not with p27, eGFP-RhoA63L, and the HR1-RBD domain of citron-K (C) or with p27, eGFP-RhoA, and the RBD domain of citron-K (D). Citron-K domains were immunoprecipitated with rabbit anti-Myc (A14) antibodies. Membranes were probed successively using mouse anti-p27 (F8), mouse anti-RhoA (26C4), and mouse anti-Myc (9E10) antibodies. The amount of each transfected protein is shown in the lower panels. (E) The last 8 aa of p27 are required for binding to citron- $\mathrm{K}$, and phosphorylation of p27 on Thr198 prevents citron-K binding. Pull-down experiments were performed with HEK293 cells transfected with citron-K, Cit- $\Delta \mathrm{N}$, or HR1-RBD using the indicated GST-p27 beads. The amounts of proteins bound to the beads or transfected in the input extracts were determined by immunoblot using the indicated antibodies. The amount of GST beads used in the assays was visualized by Coomassie staining. (F) The ability to bind citron- $\mathrm{K}$ is required for $\mathrm{p} 27^{\mathrm{CK}-}$ to cause multinucleation. HeLa cells were transfected with empty vector or vectors encoding the indicated p27 ${ }^{\mathrm{CK}}-$ mutants. Immunoblot shows the expression level of each p27mutant. In this exposure, endogenous p27 is not visible. Multinucleated cells were counted (200-500 positive cells/condition, $n=5$ ) using $\beta$-catenin and p27 staining to visualize transfected cells. ${ }^{*} P<0.05$, ${ }^{* *} P<0.01,{ }^{* * *} P<0.001,1$-way ANOVA with the Tukey-Kramer multiple comparison test; error bars represent SEM. (G) Immortalized $p 27^{-/-}$MEFs were infected with p27 ${ }^{\mathrm{CK}}$ - or different p27 ${ }^{\mathrm{CK}-}$ mutants. Multinucleated cells were quantified (500 cells/ condition, $n=3$ ). The level of p27CK- or p27CK- mutants was measured by immunoblot against p27. Results were analyzed as in F.

The phenotype caused by $27^{\mathrm{CK}-}$ is similar, albeit at approximately half the incidence, to that observed following knockdown of citron-K, suggesting that p27 only partially inhibits citron-K function. Other groups have reported slightly higher multinucleation numbers after citron-K knockdown in human cells (approximately 20\%) (39-41) or drosophila cells (approximately $30 \%)(43,44,46)$. This may be due to the fact that in all these reports, multinucleation was quantified 72 hours after siRNA treatment, in contrast to 48 hours in our experiments. Indeed, the proportion of multinucleated cells after citron-K siRNA treatment was found to increase over time $(43,46)$. A potential explanation for the partial inhibition of citron-K function by $\mathrm{p} 27$ is that aside from being a kinase, citron- $\mathrm{K}$ has a multi-domain structure and probably plays an important role as a scaffold protein, participating in the assembly of large signaling or structural complexes during cytokinesis. Citron-K contains a Ser/Thr kinase domain; a CC domain that contains RID and HR1, two regions that were proposed to participate in RhoA binding in ROCK (34), and a RBD; a Zn finger domain; a pleckstrin homology $(\mathrm{PH})$ domain; a citron homology domain (CNH); a proline-rich region; and a C-terminal PDZ binding domain (35). Citron-K is a Rho effector involved in cytokinesis, but its exact role at the molecular level remains unclear. The identification of citron-K substrates will be essential to elucidate its function during cytokinesis and other biological processes.

A number of citron-K partners have been identified: its CC domain has been involved in mediating the di- or tetramerization of the protein (57), and the C-terminal part of the protein comprising the $\mathrm{CNH} /$ Pro-rich/PDZ domains mediates binding to ROCK II, profilin IIa, LIMK, p116RIP, anillin, and Dlg5 $(38,63,64)$. In addition, other proteins involved in mitosis are known to interact with citron-K, including PRC1, KIF14, RanBPM, and Plk1, but their interaction domain on citron-K remains to be identified $(41,65$, 66). We mapped the interaction of p27 on citron-K to the HR1 region and also found a weaker interaction with the neighboring RBD domain. In binding to this region of citron-K, p27 inhibited the Rho-citron-K interaction. Moreover, expression of the HR1 domain could rescue the cytokinesis defect caused by $\mathrm{p} 27^{\mathrm{CK}-}$. In agreement with p27 interfering with citron-K binding to Rho, we found that $\mathrm{p} 27$ had no direct effect on the kinase activity of citron-K in vitro. However, we cannot exclude that p27 could interfere with citron-K function by blocking its interaction with another partner, such as PRC1, KIF14, RanBPM, or Plk1, that may bind to the same region of citron-K.

Although p27 can interact with both RhoA and citron-K, our data indicate not the formation of a ternary complex, but rather that these complexes are mutually exclusive. Our results suggest that when it is not phosphorylated on Thr198, p27 may bind to and regulate citron-K, while phosphorylation on Thr198 would preferentially target it toward RhoA (58). The most frequent cause of multinucleation in wild-type and p $^{27^{\mathrm{CK}}-}$ cells is a failure to resolve cytokinesis and undergo abscission, in which citron-K plays a critical role (43-45). Consistent with this idea, mutant forms of $\mathrm{p} 27^{\mathrm{CK}-}$ that cannot bind citron-K did not cause multinucleation. In addition, the spatial and temporal localization of other key players in cytokinesis, including MKLP1, Ect2, anillin, PRC1, and RhoA, were normal in $\mathrm{p}^{27^{\mathrm{CK}}-}$-expressing cells (data not shown).

The role of p27 we describe during cytokinesis via the regulation of citron-K was discovered through the study of $p 27^{C K-}$ mice; hence, it remains unclear at this stage what the importance of this function is in the context of wild-type p27. Given the recent implication that $\mathrm{p} 27$ participates in $\mathrm{G}_{2} / \mathrm{M}$ arrest and the maintenance of genome integrity (22-24), one could speculate that $\mathrm{p} 27$ may also delay completion of cytokinesis by interfering with citron-K activation. This delay could serve either to provide time to resolve mitotic aberrations, such as chromosome missegregation, as recently described (67), or to trigger apoptosis, as cytokinesis defects have been associated with induction of apoptosis $(47,48,68,69)$.

The nature of the defects causing multinucleation, mostly intercellular bridge reopening, is identical in cells expressing wild-type p27 and p27 ${ }^{\mathrm{CK}-}$, suggesting that the overall increased incidence

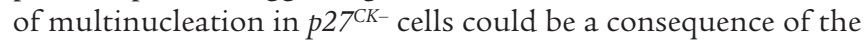
increased levels of $\mathrm{p}^{27^{\mathrm{CK}}-}$ in $\mathrm{G}_{2} / \mathrm{M}$ and a stronger effect on citron-K. In p27-null cells, there was a shift in the nature of the defects causing multinucleation (i.e., rare intercellular bridge reopening), which may reflect the loss of citron-K regulation by $\mathrm{p} 27$. However, an alternative hypothesis to explain the differences in incidence and cause of cytokinetic failure between wild-type, $p 27^{\mathrm{CK}-}$, and $p 27^{-1-}$ cells could be the inability of $\mathrm{p}^{27^{\mathrm{CK}-}}$ to interact with cyclinCDK complexes. Indeed, one could envision that wild-type p27 may either inhibit cyclin-CDKs at the mid-body during cytokinesis or participate in their targeting to specific locations by binding to citron-K. We are currently investigating these different possi- 
bilities. Interestingly, Skop et al. found that CDK1 and CDK4 are both present at the mid-body in their screen (53). Thus, while our experiments clearly indicate a role for $\mathrm{p} 27^{\mathrm{CK}-}$ during cytokinesis via citron-K regulation, the exact function of wild-type p27 during cytokinesis still requires further investigation.

This new role of p27 in cytokinesis may represent one possible explanation for the tumor-prone phenotype of $p^{27^{C K}-}$ mice (15). Indeed, cytokinesis defects are well known to result in tetraploidy, which then promotes further genomic instability through more mitotic aberrations. Thus, by increasing the frequency of cytokinesis defects leading to multinucleation, centrosome amplification, and polyploidy, $\mathrm{p}^{7^{\mathrm{CK}-}}$ may prime cells for further transforming events and tumorigenesis. Likewise, this mechanism may be relevant in the context of human cancer: while p27 levels are most frequently decreased in human cancers, a fraction of tumors maintain p27 expression, and this is frequently accompanied by a relocalization of the protein in the cytoplasm $(2,8)$. Cytoplasmic localization of p27 in tumors correlates with high tumor grade, aggressive disease, and metastasis $(2,8,13)$. p27 phosphorylation at Thr198 by kinases such as Rsk1, PKB/Akt, LKB1/AMPK, and Pim1 causes both its stabilization and cytoplasmic localization $(58,70-72)$. However, in our experiments, mutants of $\mathrm{p} 27$ that mimic Thr198 phosphorylation could no longer interact with citron-K, implying that p27 would have to be dephosphorylated on this site in late mitosis in order to regulate citron-K, although Thr198 phosphorylation appears to be highest in $G_{1}$ and $G_{1} / S$ cells $(58,71)$. Interestingly, the Ser/Thr phosphatase PPM1H was recently reported to dephosphorylate $\mathrm{p} 27$ on Thr187, thus protecting it from Skp2-mediated degradation, and loss of PPM1H conferred resistance to Herceptin treatment in cells and correlated with a trend toward poor clinical outcome in breast cancer patients (73). In this context, determining the phosphorylation status of $\mathrm{p} 27$ in mitosis and how it is regulated will be important to fully understand its role during this phase of the cell cycle. Thus, it is possible that tumor cells in which p27 is cytoplasmic (and so escape Skp2-mediated degradation) would enter mitosis with elevated levels of the protein, which could result in an increased frequency of cytokinetic failure, leading to polyploidy and increasing chromosomal instability.

\section{Methods}

Constructs and antibodies. The Myc-tagged citron-K cDNA was provided by Ferdinando Di Cunto (University of Turin, Turin, Italy) and was subcloned in the pcDNA3.1-Hygro vector (Invitrogen). Various deletion mutants of citron-K were constructed by PCR using Myc-citron-K and cloned in a pcDNA3.1-Hygro vector modified to encode a Myc-epitope tag. pRK5-MycRhoA, pCMV-Myc-RhoA63L, and peGFP-RhoA63L have been described previously (10). The HA-tagged RhoB in pIRES Puro was provided by Gilles Favre (Institut Claudius Régaud, Toulouse, France). Control, citron-K, and RhoA siRNA were purchased from Dharmacon or Santa Cruz Biotechnology Inc. Antibodies used were obtained as follows: monoclonal antibodies to citron-K, $\beta$-catenin, and Grb2 were from BD Biosciences; monoclonal antibodies anti- $\gamma$-tubulin (GTU-88) and anti- $\beta$-tubulin (TUB2.1) were from Sigma-Aldrich; rabbit polyclonal antibodies to lamin-A (H102), p27 (C19), c-Myc (A14), RhoB (119), goat polyclonal antibodies to citron (C20 and S20), and monoclonal antibodies to RhoA (26C4), c-Myc (E10), and p27 (F8) were purchased from Santa Cruz Biotechnology Inc. Secondary antibodies conjugated to HRP, CY2, CY3, and CY5 were purchased from Jackson ImmunoResearch Laboratories.

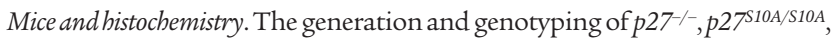
and $p 27^{C K-}$ mice was described previously $(4,14)$. Dissected tissues were fixed in $10 \%$ formalin overnight, transferred to $70 \%$ ethanol for 48 hours, and embedded in paraffin. Three-micrometer tissue sections were stained with hematoxylin and eosin. Bright field images were acquired on a Nikon 90i microscope with a Nikon DS-Fi1 camera using Nikon NIS-Br software. Feulgen staining and quantification of hepatocyte ploidy were performed as described previously (21).

Cell culture and transfections. All cells were grown at $37^{\circ} \mathrm{C}$ and $5 \% \mathrm{CO}_{2}$ in DMEM, 2 mM GlutaMAX (Invitrogen), $4.5 \mathrm{~g} / \mathrm{l}$ glucose supplemented with $10 \%$ fetal calf serum, $0.1 \mathrm{mM}$ nonessential amino acids, $2 \mu \mathrm{g} / \mathrm{ml}$ penicillin-streptomycin, and $1 \mathrm{mM}$ sodium pyruvate. All tissue culture reagents were from Life Technologies. Primary MEFs were prepared as described previously (74). MEFs were immortalized by infection with retroviruses encoding the human papilloma virus E6 protein and hygromycin selection. MEFs were infected with a pWZL vector containing $\mathrm{p} 27^{\mathrm{CK}-}$ selected with $2 \mu \mathrm{g} / \mathrm{ml}$ blasticidin or PQCXIP p27 ${ }^{\text {CK- }}$ T198 mutants with puromycin selection. Transfection of primary MEFs with HR1 or GFP was performed using the Trans-IT 2020 reagent (Mirus), following the manufacturer's instructions. HeLa cells were transfected using FuGENE 6 (Roche) according to the manufacturer's instructions, with a typical transfection efficiency of greater than $50 \%$ as measured by GFP expression. Transient transfections of HEK293 cells were performed by the calcium phosphate method for 24 hours. For siRNA transfection in HeLa cells, the N-TER nanoparticle siRNA transfection system (Sigma-Aldrich) was used following the manufacturer's instructions.

Flow cytometry. Cells were trypsinized, rinsed once in PBS, and resuspended in $300 \mathrm{ml}$ PBS. Cells were fixed by addition of $700 \mu \mathrm{l}$ of $99 \%$ ethanol. Samples were kept at $4^{\circ} \mathrm{C}$. Fixed cells were pelleted and resuspended in PBS containing RNase $\mathrm{A}(50 \mathrm{mg} / \mathrm{ml})$ and propidium iodide $(50 \mathrm{mg} / \mathrm{ml})$ and then incubated for 30 minutes at $37^{\circ} \mathrm{C}$. Cell cycle analysis was done on a FACScan (BD).

Immunofluorescence. Cells were seeded on coverslips and grown overnight before further treatment. After appropriate treatment or transfection, cells were fixed with $2 \%$ PFA in PBS for 20 minutes at $37^{\circ} \mathrm{C}$ (for p27, lamin-A, c-Myc, and $\beta$-catenin staining) or with $1 \%$ PFA for 3 minutes at $37^{\circ} \mathrm{C}$ and then methanol at $-20^{\circ} \mathrm{C}$ for 5 minutes (for citron- $\mathrm{K}, \gamma$-tubulin, and $\beta$-tubulin staining). For p27 staining in mitotic cells, cells were permeabilized for 3 minutes with digitonin $(40 \mu \mathrm{g} / \mathrm{ml})$ in PBS prior to PFA/methanol fixation as described above. For immunostaining, cells were permeabilized for 3 minutes with PBS $0.2 \%$ Triton X-100, rinsed three times for 5 minutes in PBS, and incubated for 1 hour at $37^{\circ} \mathrm{C}$ with primary antibodies diluted in $\mathrm{PBS} / 3 \% \mathrm{BSA} / 0.05 \%$ Tween and $0.08 \%$ sodium azide at the indicated concentrations. After three 5-minute washes in PBS, cells were incubated for 30 minutes at $37^{\circ} \mathrm{C}$ with Cy2-, Cy3-, or Cy5-conjugated secondary antibodies at 1:400 dilution. Coverslips were washed 3 times for 5 minutes in PBS, with the first wash containing $0.1 \mu \mathrm{g} / \mathrm{ml}$ Hoechst H33342, and mounted on glass slides. Images were acquired on a Nikon Eclipse 90i microscope equipped with a CoolSnap HQ2 camera using NIS-Br software (Nikon).

Videomicroscopy. MEFs were seeded in Lab-Tek chambered coverglass (Nunc) and treated for 8 hours with $9 \mu \mathrm{M}$ RO3306 (Calbiochem). Cells were rinsed twice in medium and put in an incubation chamber equilibrated at $5 \% \mathrm{CO}_{2}$ and $37^{\circ} \mathrm{C}$. A videomicroscopy experiment was performed during 20 hours using a Leica DMI6000B microscope equipped with a CoolSnap HQ2 camera and using MetaMorph 7.6 software (MDS Analytical Technologies).

Western blotting. Cells were lysed in IP buffer containing $50 \mathrm{mM}$ HEPES pH 7.5, 150 mM NaCl, 1 mM EDTA, 2.5 mM EGTA, 0.1\% Tween-20, 10\% glycerol, and 1\% NP-40 complemented with $1 \mathrm{mM} \mathrm{DTT,} 10 \mathrm{mM} \beta$-glycerophosphate, $10 \mathrm{mM} \mathrm{NaF}, 10 \mathrm{mM}$ sodium orthovanadate, $10 \mu \mathrm{g} / \mathrm{ml}$ leupeptin, $10 \mu \mathrm{g} / \mathrm{ml}$ aprotinin, and $10 \mu \mathrm{g} / \mathrm{ml}$ pepstatin A. After sonication for 10 seconds, cell extracts were centrifuged for 5 minutes at $14,000 \mathrm{~g}$. Proteins were separated on SDS-PAGE $12 \%$ gels or $4 \%-15 \%$ gradient gels (Bio-Rad) and transferred onto polyvinylidene difluoride membranes (Mil- 
lipore). After blocking for 1 hour in PBS/0.1\% Tween-20/10\% milk, membranes were incubated overnight at $4{ }^{\circ} \mathrm{C}$ with primary antibodies diluted in PBS $/ 0.1 \%$ Tween-20/5\% milk. Membranes were rinsed three times in PBS/0.1\% Tween-20 and incubated with secondary HRP-conjugated antibodies for 4 hours at room temperature. Immunodetection was performed with Western Lightning Chemiluminescence and -Plus reagents (PerkinElmer). Membrane stripping was performed by agitating for 30 minutes in glycine $\mathrm{pH} 1.5$, rinsing three times in PBS/0.1\% Tween-20, and blocking prior to probing with a new antibody.

Co-immunoprecipitations and pull-down assays. HEK293 cell extracts were prepared as described above using $800 \mu \mathrm{l}$ IP buffer to lyse a $100-\mathrm{mm}$ plate. For each immunoprecipitation, $100 \mu \mathrm{l}$ of cell lysate were incubated with $15 \mu \mathrm{l}$ protein A agarose beads (Repligen) and $4 \mu \mathrm{g}$ of the indicated antibody in $500 \mu \mathrm{l}$ IP buffer during 4 hours at $4^{\circ} \mathrm{C}$. After washing three times in IP buffer, bead pellets were resuspended in $10 \mu \mathrm{l} 4 \times$ sample buffer, boiled, and subjected to Western blotting. Protein expression was verified by immunoblot on $8 \mu \mathrm{l}$ of each cell extract. For pull-down assays, antibody and protein A beads were replaced by $10 \mu \mathrm{l}$ GST or the indicated GSTfusion protein bound to Glutathione Sepharose 4B beads (GE Healthcare), and the same protocol was followed. For endogenous p27/citron-K immunoprecipitations, $1.5 \mathrm{mg}$ of proteins of HeLa cell lysates treated with nocodazole (14 hours, $250 \mathrm{nM}$ ) or nocodazole (14 hours) and purvalanol A (45 minutes, $22.5 \mu \mathrm{M}$ ) were used.

Statistics. Statistical analyses were performed using GraphPad Instat 3.06 software. Differences between groups were evaluated using 1-way
ANOVA, and the specific tests used are indicated in the figure legends. In Figures 3 and 6, 2-tailed Student's $t$ test was used. Data are presented as mean $\pm \mathrm{SD}$ or SEM as indicated, and a $P$ value less than 0.05 was considered statistically significant.

Study approval. Mice used in this study were maintained and procedures performed with the approval of the Comite d'éthique régional Midi-Pyrénées.

\section{Acknowledgments}

We are grateful to Ferdinando di Cunto (University of Turin) and Gilles Favre (Institut Claudius Régaud) for providing reagents. We thank Thomas Mangeat for technical assistance with the videomicroscopy platform. M.P. Serres is supported by a studentship from the Association pour la Recherche sur le Cancer. This work was supported by NIH grant 1R01CA118043 to J.M. Roberts. A. Besson is supported by grants from the Association pour la Recherche sur le Cancer, Ligue Nationale Contre le Cancer, and Institut National du Cancer.

Received for publication August 5, 2011, and accepted in revised form December 14, 2011.

Address correspondence to: Arnaud Besson, CRCT UMR1037 INSERM, 118 Route de Narbonne, Bâtiment 4R3b1, 31062 Toulouse Cedex 9, France. Phone: 33.561556435; Fax: 33.561558109; E-mail: arnaud.besson@inserm.fr.
1. Sherr CJ, Roberts JM. CDK inhibitors: positive and negative regulators of G1-phase progression. Genes Dev. 1999;13(12):1501-1512.

2. Besson A, Dowdy SF, Roberts JM. CDK Inhibitors: cell cycle regulators and beyond. Dev Cell. 2008; 14(2):159-169.

3. Fero ML, Randel E, Gurley KE, Roberts JM, Kemp CJ. The murine gene p27Kip1 is haplo-insufficient for tumour suppression. Nature. 1998; 396(6707):177-180.

4. Fero ML, et al. A syndrome of multiorgan hyperplasia with features of gigantism, tumorigenesis, and female sterility in p27(Kip1)-deficient mice. Cell. 1996;85(5):733-744.

5. Kiyokawa H, et al. Enhanced growth of mice lacking the cyclin-dependent kinase inhibitor function of p27Kip1. Cell. 1996;85(5):721-732.

6. Nakayama K, et al. Mice lacking p27Kip1 display increased body size, multiple organ hyperplasia, retinal dysplasia, and pituitary tumors. Cell. 1996; 85(5):707-720.

7. Porter PL, et al. Expression of cell-cycle regulators $\mathrm{p} 27 \mathrm{Kip} 1$ and cyclin $\mathrm{E}$, alone and in combination, correlate with survival in young breast cancer patients. Nat Med. 1997;3(2):222-225.

8. Chu IM, Hengst L, Slingerland JM. The Cdk inhibitor p27 in human cancer: prognostic potential and relevance to anticancer therapy. Nat Rev Cancer. 2008;8(4):253-267.

9. Garrett-Engele CM, et al. A mechanism misregulating $\mathrm{p} 27$ in tumors discovered in a functional genomic screen. PLoS Genet. 2007;3(12):e219.

10. Besson A, Gurian-West M, Schmidt A, Hall A, Roberts JM. p27Kip1 modulates cell migration through the regulation of RhoA activation. Genes Dev. 2004;18(8):862-876.

11. Nguyen L, et al. p27Kip1 independently promotes neuronal differentiation and migration in the cerebral cortex. Genes Dev. 2006;20(11):1511-1524.

12. Wu FY, et al. Reduction of cytosolic p27(Kip1) inhibits cancer cell motility, survival, and tumorigenicity. Cancer Res. 2006;66(4):2162-2172.

13. Denicourt C, Saenz CC, Datnow B, Cui XS, Dowdy SF. Relocalized p27Kip1 tumor suppressor func- tions as a cytoplasmic metastatic oncogene in melanoma. Cancer Res. 2007;67(19):9238-9243.

14. Besson A, Gurian-West M, Chen X, Kelly-Spratt KS, Kemp CJ, Roberts JM. A pathway in quiescent cells that controls p27Kip1 stability, subcellular localization, and tumor suppression. Genes Dev. 2006;20(1):47-64.

15. Besson A, et al. Discovery of an oncogenic activity in $\mathrm{p} 27 \mathrm{Kip} 1$ that causes stem cell expansion and a multiple tumor phenotype. Genes Dev. 2007; 21(14):1731-1746.

16. Serres M, Concha C, Daburon V, Gurian-West M, Roberts JM, Besson A. Cytoplasmic p27 is oncogenic and cooperates with Ras both in vivo and in vitro. Oncogene. 2011;30(25):2846-2858.

17. Malek NP, Sundberg H, McGrew S, Nakayama $\mathrm{K}$, Kyriakides TR, Roberts JM. A mouse knock-in model exposes sequential proteolytic pathways that regulate p27Kip1 in G1 and S phase. Nature. 2001;413(6853):323-327.

18. Coats S, Flanagan WM, Nourse J, Roberts JM. Requirements of $\mathrm{p} 27 \mathrm{Kip} 1$ for restriction point control of the fibroblast cell cycle. Science. 1996; 272(5263):877-880.

19. Nakayama K, et al. Targeted disruption of Skp2 results in accumulation of cyclin E and p27(Kip1), polyploidy and centrosome overduplication. EMBO J. 2000;19(9):2069-2081.

20. Nakayama K, et al. Skp2-mediated degradation of p27 regulates progression into mitosis. Dev Cell. 2004;6(5):661-672.

21. Kossatz U, Dietrich N, Zender L, Buer J, Manns MP, Malek NP. Skp2-dependent degradation of $\mathrm{p} 27 \mathrm{kip} 1$ is essential for cell cycle progression. Genes Dev. 2004;18(21):2602-2607.

22. See WL, Miller JP, Squatrito M, Holland E, Resh MD, Koff A. Defective DNA double-strand break repair underlies enhanced tumorigenesis and chromosomal instability in $\mathrm{p}^{27}$-deficient mice with growth factor-induced oligodendrogliomas. Oncogene. 2010;29(12):1720-1731.

23. Cuadrado M, Gutierrez-Martinez P, Swat A, Nebreda AR, Fernandez-Capetillo O. p27Kip1 stabilization is essential for the maintenance of cell cycle arrest in response to DNA damage. Cancer Res. 2009; 69(22):8726-8732.

24. Payne SR, et al. p27kip1 deficiency impairs G2/M arrest in response to DNA damage, leading to an increase in genetic instability. Mol Cell Biol. 2008; 28(1):258-268.

25. Glotzer M. Animal cell cytokinesis. Annu Rev Cell Dev Biol. 2001;17:351-386.

26. Guizetti J, Gerlich DW. Cytokinetic abscission in animal cells. Semin Cell Dev Biol. 2010;21(9):909-916.

27. Glotzer M. The molecular requirements for cytokinesis. Science. 2005;307(5716):1735-1739.

28. Piekny A, Werner M, Glotzer M. Cytokinesis: welcome to the Rho zone. Trends Cell Biol. 2005; 15(12):651-658

29. Matsumura F. Regulation of myosin II during cytokinesis in higher eukaryotes. Trends Cell Biol. 2005;15(7):371-377.

30. Watanabe $\mathrm{S}$, et al. $\mathrm{mDia} 2$ induces the actin scaffold for the contractile ring and stabilizes its position during cytokinesis in NIH 3T3 cells. Mol Biol Cell. 2008;19(5):2328-2338.

31. Di Cunto F, et al. Citron rho-interacting kinase, a novel tissue-specific ser/thr kinase encompassing the Rho-Rac-binding protein Citron.J Biol Chem. 1998;273(45):29706-29711.

32. Madaule $\mathrm{P}$, et al. Role of citron kinase as a target of the small GTPase Rho in cytokinesis. Nature. 1998; 394(6692):491-494.

33. Zhao ZS, Manser E. PAK and other Rho-associated kinases - effectors with surprisingly diverse mechanisms of regulation. Biochem J. 2005; 386(pt 2):201-214.

34. Blumenstein L, Ahmadian MR. Models of the cooperative mechanism for Rho effector recognition: implications for RhoA-mediated effector activation. J Biol Chem. 2004;279(51):53419-53426.

35. Madaule P, et al. A novel partner for the GTPbound forms of rho and rac. FEBS Lett. 1995; 377(2):243-248.

36. Madaule P, Furuyashiki T, Eda M, Bito H, Ishizaki T, Narumiya S. Citron, a Rho target that affects contractility during cytokinesis. Microsc Res Tech. 2000; 49(2):123-126. 
37. Eda M, et al. Rho-dependent transfer of Citronkinase to the cleavage furrow of dividing cells. J Cell Sci. 2001;114(pt 18):3273-3284.

38. Gai $\mathrm{M}$, et al. Citron kinase controls abscission through RhoA and Anillin. Mol Biol Cell. 2011; 22(20):3768-3778

39. Fu Y, Huang J, Wang KS, Zhang X, Han ZG. RNA interference targeting CITRON can significantly inhibit the proliferation of hepatocellular carcinoma cells. Mol Biol Rep. 2011;38(2):693-702

40. Kamijo K, et al. Dissecting the role of Rho-mediated signaling in contractile ring formation. $\mathrm{Mol}$ Biol Cell. 2006;17(1):43-55.

41. Gruneberg U, et al. KIF14 and citron kinase act together to promote efficient cytokinesis. J Cell Biol. 2006;172(3):363-372.

42. Neumann B, et al. Phenotypic profiling of the human genome by time-lapse microscopy reveals cell division genes. Nature. 2010;464(7289):721-727.

43. Naim V, Imarisio S, Di Cunto F, Gatti M, Bonaccorsi S. Drosophila citron kinase is required for the final steps of cytokinesis. Mol Biol Cell. 2004; 15(11):5053-5063.

44. Echard A, Hickson GR, Foley E, O'Farrell PH. Terminal cytokinesis events uncovered after an RNA screen. Curr Biol. 2004;14(18):1685-1693.

45. Shandala T, Gregory SL, Dalton HE, Smallhorn M, Saint R. Citron kinase is an essential effector of the Pbl-activated Rho signalling pathway in Drosophila melanogaster. Development. 2004; 131(20):5053-5063.

46. D'Avino PP, Savoian MS, Glover DM. Mutations in sticky lead to defective organization of the contractile ring during cytokinesis and are enhanced by Rho and suppressed by Rac. J Cell Biol. 2004;166(1):61-71.

47. Di Cunto F, Imarisio S, Camera P, Boitani C, Altruda F, Silengo L. Essential role of citron kinase in cytokinesis of spermatogenic precursors. J Cell Sci. 2002; 115(pt 24):4819-4826.

48. Di Cunto F, et al. Defective neurogenesis in citron kinase knockout mice by altered cytokinesis and massive apoptosis. Neuron. 2000;28(1):115-127.

49. Liu H, Di Cunto F, Imarisio S, Reid LM. Citron kinase is a cell cycle-dependent, nuclear protein required for G2/M transition of hepatocytes. J Biol Chem. 2003;278(4):2541-2548.

50. Yamashiro S, et al. Citron kinase, a Rho-depen- dent kinase, induces di-phosphorylation of regulatory light chain of myosin II. Mol Biol Cell. 2003; 14(5):1745-1756.

51. Montagnoli A, et al. Ubiquitination of p27 is regulated by Cdk-dependent phosphorylation and trimeric complex formation. Genes Dev. 1999; 13(9):1181-1189.

52. Vlach J, Hennecke S, Amati B. Phosphorylation-dependent degradation of the cyclin-dependent kinase inhibitor p27 Kip1. EMBO J. 1997; 16(17):5334-5344.

53. Skop AR, Liu H, Yates J 3rd, Meyer BJ, Heald R Dissection of the mammalian midbody proteome reveals conserved cytokinesis mechanisms. Science. 2004;305(5680):61-66.

54. Kuo TC, et al. Midbody accumulation through evasion of autophagy contributes to cellular reprogramming and tumorigenicity. Nat Cell Biol. 2011; 13(10):1214-1223.

55. Vega FM, Fruhwirth G, Ng T, Ridley AJ. RhoA and RhoC have distinct roles in migration and invasion by acting through different targets. J Cell Biol. 2011;193(4):655-665.

56. Hauck L, et al. Protein kinase CK2 links extracellular growth factor signaling with the control of p27(Kip1) stability in the heart. Nat Med. 2008;14(3):315-324.

57. Zhang W, Benson DL. Targeting and clustering citron to synapses. Mol Cell Neurosci. 2006;31(1):26-36.

58. Larrea MD, et al. RSK1 drives p27Kip1 phosphorylation at T198 to promote RhoA inhibition and increase cell motility. Proc Natl Acad Sci U S A. 2009;106(23):9268-9273

59. Hoshino D, Tomari T, Nagano M, Koshikawa N, Seiki M. A novel protein associated with membranetype 1 matrix metalloproteinase binds p27(kip1) and regulates RhoA activation, actin remodeling, and matrigel invasion. J Biol Chem. 2009; 284(40):27315-27326.

60. Papakonstanti EA, Ridley AJ, Vanhaesebroeck B. The p110delta isoform of PI 3-kinase negatively controls RhoA and PTEN. Embo J. 2007;26(13):3050-3061.

61. Zhong L, Georgia S, Tschen SI, Nakayama K, Bhushan A. Essential role of Skp2-mediated p27 degradation in growth and adaptive expansion of pancreatic beta cells. J Clin Invest. 2007;117(10):2869-2876.

62. Guidotti JE, Bregerie O, Robert A, Debey P, Brechot C, Desdouets C. Liver cell polyploidization: a pivotal role for binuclear hepatocytes. J Biol Chem. 2003;278(21):19095-19101.

63. Chang Y, Klezovitch O, Walikonis RS, Vasioukhin $\mathrm{V}$, LoTurco JJ. Discs large 5 is required for polarization of citron kinase in mitotic neural precursors. Cell Cycle. 2010;9(10):1990-1997.

64. Camera P, et al. Citron-N is a neuronal Rho-associated protein involved in Golgi organization through actin cytoskeleton regulation. Nat Cell Biol. 2003;5(12):1071-1078

65. Chang Y, Paramasivam M, Girgenti MJ, Walikonis RS, Bianchi E, LoTurco JJ. RanBPM regulates the progression of neuronal precursors through $\mathrm{M}$ phase at the surface of the neocortical ventricular zone. Dev Neurobiol. 2010;70(1):1-15.

66. Lowery DM, et al. Proteomic screen defines the Polobox domain interactome and identifies Rock 2 as a Plk1 substrate. EMBO J. 2007;26(9):2262-2273.

67. Steigemann P, et al. Aurora B-mediated abscission checkpoint protects against tetraploidization. Cell. 2009;136(3):473-484.

68. Conn CW, Hennigan RF, Dai W, Sanchez Y, Stambrook PJ. Incomplete cytokinesis and induction of apoptosis by overexpression of the mammalian pololike kinase, Plk3. Cancer Res. 2000;60(24):6826-6831.

69. Pohl C, Jentsch S. Final stages of cytokinesis and midbody ring formation are controlled by BRUCE. Cell. 2008;132(5):832-845.

70. Morishita D, Katayama R, Sekimizu K, Tsuruo T, Fujita N. Pim kinases promote cell cycle progression by phosphorylating and down-regulating p27Kip1 at the transcriptional and posttranscriptional levels. Cancer Res. 2008;68(13):5076-5085.

71. Kossatz U, et al. C-terminal phosphorylation controls the stability and function of $\mathrm{p} 27 \mathrm{kip} 1 . E M B O J$. 2006;25(21):5159-5170.

72. Liang J, et al. The energy sensing LKB1-AMPK pathway regulates $\mathrm{p} 27$ (kip 1 ) phosphorylation mediating the decision to enter autophagy or apoptosis. Nat Cell Biol. 2007;9(2):218-224.

73. Lee-Hoeflich S, et al. PPM1H is a p27 phosphatase implicated in trastuzumab resistance. Cancer Discovery. 2011;1:326-337.

74. Spector DL. Isolation of fibroblasts. In: Spector D, Goldman R, Leinwand L, eds. Cells: A Laboratory Manual. New York, New York USA: Cold Spring Harbor Laboratory Press; 1997:4.3-4.7. 